\title{
Millimetre observations of southern translucent clouds ${ }^{\star}$
}

\author{
Roland Gredel $^{1}$, Ewine F. van Dishoeck ${ }^{2}$, and John H. Black ${ }^{3}$ \\ ${ }^{1}$ European Southern Observatory, Casilla 19001, Santiago 19, Chile \\ 2 Sterrewacht Leiden, P.O. Box 9513, NL-2300 RA Leiden, The Netherlands \\ ${ }^{3}$ Steward Observatory, University of Arizona, Tucson, AZ 85721, USA
}

Received 28 May 1993 / Accepted 6 November 1993

\begin{abstract}
Millimetre emission line observations of ${ }^{12} \mathrm{CO} J=1 \rightarrow 0$ are presented for a sample of translucent molecular clouds previously studied by optical absorption lines towards background stars. The $\mathrm{CO}$ maps provide information on the extent, structure, mass and kinematics of the regions. In some clouds, the emission is characterized by a single component which does not vary much across the region. In other cases, multiple close-lying components or sheets are found, which may vary in a self-similar manner across the cloud. None of the clouds is close to simple virial equilibrium. Sensitive searches for ${ }^{13} \mathrm{CO}$ and $\mathrm{C}^{18} \mathrm{O} J=1 \rightarrow 0$ emission have been made towards the stellar positions. $\mathrm{C}^{18} \mathrm{O}$ has been detected in only 5 clouds, most of which have extinctions well in excess of $2 \mathrm{mag}$. The inferred ${ }^{13} \mathrm{CO} / \mathrm{C}^{18} \mathrm{O}$ abundance ratios range from $7-25$, and the lower limits from $>13$ to $>35$. These values are as much as five times larger than the overall interstellar $\left(\left[{ }^{13} \mathrm{C}\right] \cdot\left[{ }^{16} \mathrm{O}\right]\right) /\left(\left[{ }^{12} \mathrm{C}\right] \cdot\left[{ }^{18} \mathrm{O}\right]\right)$ ratio, suggesting that isotopeselective photodissociation plays a role in at least some of the clouds. Searches for other molecules at millimetre wavelengths have been made for a few of the best characterized clouds. Surprisingly, no emission was detected from the $\mathrm{C}_{2} \mathrm{H}$ or $\mathrm{C}_{3} \mathrm{H}_{2}$ molecules, even though the abundances of diatomic $\mathrm{C}_{2}$ and $\mathrm{CH}$ are quite large. On the other hand, the abundance of $\mathrm{HCO}^{+}$appears comparable to that found in denser clouds, and the abundance of HCN may be up to an order of magnitude larger than the predictions of models in two clouds.
\end{abstract}

Key words: ISM: abundances - ISM: molecules - radio lines: molecular - ISM: clouds - ISM: structure

\section{Introduction}

In a recent series of papers, we have presented optical absorption line observations of a sample of southern translucent clouds (van Dishoeck \& Black 1989; Gredel et al. 1991, 1993; Gredel et al. 1992). These clouds have visual extinctions in the range

Send offprint requests to: $\mathrm{R}$. Gredel

* Based on observations obtained at SEST at the European Southern Observatory, La Silla, Chile
$A_{V}=1-5 \mathrm{mag}$, and are termed translucent because photons from the interstellar radiation field can influence the chemistry. The optical observations have resulted in column densities of $\mathrm{CH}$, $\mathrm{CH}^{+}, \mathrm{CN}$ and $\mathrm{C}_{2}$ towards the stars, have allowed determination of the kinetic temperature, density and electron fraction of the foreground material, and have provided constraints on the kinematics through determinations of the Doppler parameter along the lines of sight. We present here complementary millimetre observations of $\mathrm{CO}$ and other species for the same set of clouds. The aim of this work is twofold. First, maps of $\mathrm{CO}$ around the stars will give information on the two-dimensional spatial and kinematic structure of the cloud on scales of a few arcmin, and will allow estimates of the cloud mass. Second, millimetre observations of molecules such as $\mathrm{CS}, \mathrm{C}_{2} \mathrm{H}$ and $\mathrm{HCO}^{+}$, which have not been studied optically but which are expected to be significant in translucent clouds, will yield important tests of the chemistry. Preliminary results of the CO observations towards the stars were presented in van Dishoeck et al. (1991) and Gredel et al. (1991).

The first aspect of this work has been illustrated by Jannuzi et al. (1988) for the cloud towards HD 169454, and by Gredel et al. (1992) for the high-latitude cloud towards HD 210121. In both cases, $\mathrm{CO}$ observations of high spatial resolution $\left(<1^{\prime}\right.$ spacing) were presented and compared with the optical data. CO maps of other translucent and high-latitude clouds without complementary optical observations have been obtained by other workers, although usually at rather low angular resolution, e.g. Magnani et al. (1985) [20' spacing], Keto \& Myers (1986) [8'], de Vries et al. (1987) [8']. Only a few maps have been made at similar or higher resolution (e.g. Falgarone \& Pérault 1988, 22"; Pound et al. 1990, 1.5'; Falgarone et al. 1991, 2030"; Turner et al. 1992, 2'; Stark 1993, 1'). Evidence of spatial structure appears on all scales, down to the resolution of the telescope. The data presented here were obtained with $22^{\prime \prime}-1^{\prime}$ spacing. An interesting related question is the behavior of the isotopic species ${ }^{13} \mathrm{CO}$ and $\mathrm{C}^{18} \mathrm{O}$ with variations in ${ }^{12} \mathrm{CO}$ line strengths, since fractionation effects are expected to play an important role in these translucent clouds (van Dishoeck \& Black 1988). 
Table 1. CO observations

\begin{tabular}{|c|c|c|c|c|c|c|c|c|c|c|c|c|}
\hline \multirow[b]{2}{*}{ Star } & \multicolumn{3}{|c|}{${ }^{12} \mathrm{CO}(1-0)$} & \multirow[b]{2}{*}{$\begin{array}{l}T_{A}^{*} \\
\mathrm{~K}\end{array}$} & \multicolumn{3}{|c|}{${ }^{13} \mathrm{CO}(1-0)$} & \multirow[b]{2}{*}{$\begin{array}{l}T_{A}^{*} \\
\mathrm{~K}\end{array}$} & \multicolumn{3}{|c|}{$\mathrm{C}^{18} \mathrm{O}(1-0)$} & \multirow[b]{2}{*}{$\begin{array}{l}T_{A}^{*} \\
\mathrm{~K}\end{array}$} \\
\hline & $\begin{array}{l}\int_{\mathrm{K} \mathrm{km} \mathrm{s}^{-1}} T_{\boldsymbol{A}}^{*} d V \\
\end{array}$ & $\begin{array}{l}V_{L S R} \\
\mathrm{~km} \mathrm{~s}^{-1}\end{array}$ & $\begin{array}{l}\Delta V \\
\mathrm{~km} \mathrm{~s}^{-1}\end{array}$ & & $\begin{array}{l}\int T_{A}^{*} d V \\
\mathrm{~K} \mathrm{~km} \mathrm{~s}\end{array}$ & $\begin{array}{l}V_{L S R} \\
\mathrm{~km} \mathrm{~s}^{-1} \\
\end{array}$ & $\begin{array}{l}\Delta V \\
\mathrm{~km} \mathrm{~s}^{-1}\end{array}$ & & $\int_{\mathrm{K} \mathrm{km} \mathrm{s}} T_{A}^{*} d V$ & $\begin{array}{l}V_{L S R} \\
\mathrm{~km} \mathrm{~s}^{-1}\end{array}$ & $\begin{array}{l}\Delta V \\
\mathrm{~km} \mathrm{~s}^{-1}\end{array}$ & \\
\hline HD 29647 & $\begin{array}{l}5.7 \\
5.6\end{array}$ & $\begin{array}{l}5.2 \\
7.1\end{array}$ & $\begin{array}{l}1.6 \\
2.2\end{array}$ & $\begin{array}{l}3.4 \\
2.4\end{array}$ & $\begin{array}{l}2.40 \\
1.71\end{array}$ & $\begin{array}{l}5.3 \\
6.7\end{array}$ & $\begin{array}{l}1.0 \\
1.2\end{array}$ & $\begin{array}{l}2.37 \\
1.36\end{array}$ & $\begin{array}{l}\cdots \\
\cdots\end{array}$ & $\begin{array}{l}\cdots \\
\cdots\end{array}$ & $\begin{array}{l}\cdots \\
\cdots\end{array}$ & $\begin{array}{l}\cdots \\
\cdots\end{array}$ \\
\hline HD 26571 & 5.6 & 10.3 & 1.7 & 3.2 & 0.59 & 10.4 & 1.2 & 0.47 & $\cdots$ & $\ldots$ & $\cdots$ & $\ldots$ \\
\hline HD 37903 & $\begin{array}{r}6.7 \\
88.4\end{array}$ & $\begin{array}{r}6.0 \\
10.2\end{array}$ & $\begin{array}{l}2.0 \\
2.8\end{array}$ & $\begin{array}{r}3.2 \\
29.4\end{array}$ & $\begin{array}{r}1.73 \\
19.51\end{array}$ & $\begin{array}{r}9.9 \\
10.2\end{array}$ & $\begin{array}{l}1.2 \\
1.9\end{array}$ & $\begin{array}{l}1.36 \\
9.44\end{array}$ & $\begin{array}{l}1.73 \\
0.75\end{array}$ & $\begin{array}{r}9.9 \\
10.8\end{array}$ & $\begin{array}{l}1.2 \\
1.7\end{array}$ & $\begin{array}{l}1.36 \\
0.43\end{array}$ \\
\hline HD 53367 & $\begin{array}{r}4.2 \\
12.0 \\
18.2\end{array}$ & $\begin{array}{l}15.4 \\
16.8 \\
18.6\end{array}$ & $\begin{array}{l}2.0 \\
2.0 \\
2.0\end{array}$ & $\begin{array}{l}2.0 \\
5.6 \\
8.6\end{array}$ & $\begin{array}{r}\ldots \\
7.35 \\
3.56\end{array}$ & $\begin{array}{r}\ldots \\
17.0 \\
18.4\end{array}$ & $\begin{array}{l}\ldots \\
1.6 \\
1.5\end{array}$ & $\begin{array}{c}\ldots \\
4.46 \\
2.22\end{array}$ & $\begin{array}{l}\ldots \\
0.81 \\
0.43\end{array}$ & $\begin{array}{c}\ldots \\
16.9 \\
17.9\end{array}$ & $\begin{array}{l}\ldots \\
1.0 \\
1.0\end{array}$ & $\begin{array}{l}\ldots \\
0.76 \\
0.40\end{array}$ \\
\hline $\begin{array}{l}\text { HD } 62542 \\
(4.7,6)\end{array}$ & $\begin{array}{l}12.8 \\
12.7\end{array}$ & $\begin{array}{l}-4.2 \\
-5.0\end{array}$ & $\begin{array}{l}1.5 \\
1.4\end{array}$ & $\begin{array}{l}7.8 \\
8.7\end{array}$ & $\begin{array}{l}1.02 \\
3.40\end{array}$ & $\begin{array}{l}-4.2 \\
-5.1\end{array}$ & $\begin{array}{l}1.1 \\
0.9\end{array}$ & $\begin{array}{l}0.84 \\
3.47\end{array}$ & $\begin{array}{l}0.02 \\
0.17\end{array}$ & $\begin{array}{l}-4.1 \\
-5.1\end{array}$ & $\begin{array}{l}0.4 \\
0.6\end{array}$ & $\begin{array}{l}0.06 \\
0.29\end{array}$ \\
\hline HD 63804 & $\begin{array}{l}1.9 \\
0.8\end{array}$ & $\begin{array}{l}18.5 \\
22.0\end{array}$ & $\begin{array}{l}1.1 \\
2.6\end{array}$ & $\begin{array}{l}1.7 \\
0.3\end{array}$ & $\begin{array}{l}0.09 \\
0.06\end{array}$ & $\begin{array}{l}18.5 \\
22.1\end{array}$ & $\begin{array}{l}0.7 \\
0.7\end{array}$ & $\begin{array}{l}0.12 \\
0.08\end{array}$ & $\begin{array}{l}\cdots \\
\cdots\end{array}$ & $\begin{array}{l}\cdots \\
\cdots\end{array}$ & $\begin{array}{l}\cdots \\
\cdots\end{array}$ & $\begin{array}{l}\cdots \\
\cdots\end{array}$ \\
\hline HD 73882 & $\begin{array}{r}11.1 \\
6.0 \\
5.6\end{array}$ & $\begin{array}{r}5.9 \\
8.9 \\
11.2\end{array}$ & $\begin{array}{l}2.8 \\
1.8 \\
2.1\end{array}$ & $\begin{array}{l}3.7 \\
3.2 \\
2.5\end{array}$ & $\begin{array}{l}1.48 \\
2.17 \\
0.67\end{array}$ & $\begin{array}{r}6.0 \\
9.7 \\
11.8\end{array}$ & $\begin{array}{l}2.5 \\
1.6 \\
2.2\end{array}$ & $\begin{array}{l}0.57 \\
1.30 \\
0.29\end{array}$ & $\begin{array}{l}\ldots \\
\cdots \\
\cdots\end{array}$ & $\begin{array}{l}\ldots \\
\ldots \\
\cdots\end{array}$ & $\begin{array}{l}\ldots \\
\ldots \\
\ldots\end{array}$ & $\begin{array}{l}\cdots \\
\cdots \\
\cdots\end{array}$ \\
\hline HD 75149 & 10.8 & 22.8 & 1.9 & 5.4 & 1.98 & 23.0 & 1.3 & 1.43 & $\cdots$ & $\cdots$ & $\ldots$ & $\cdots$ \\
\hline HD 78344 & $\begin{array}{l}5.5 \\
1.0 \\
4.0\end{array}$ & $\begin{array}{l}3.0 \\
4.8 \\
6.5\end{array}$ & $\begin{array}{l}2.2 \\
0.7 \\
1.8\end{array}$ & $\begin{array}{l}2.3 \\
1.3 \\
2.0\end{array}$ & $\begin{array}{l}\cdots \\
\cdots \\
\cdots\end{array}$ & $\begin{array}{l}\cdots \\
\cdots \\
\cdots\end{array}$ & $\begin{array}{l}\ldots \\
\ldots \\
\ldots\end{array}$ & $\begin{array}{l}\cdots \\
\cdots \\
\cdots\end{array}$ & $\begin{array}{l}\cdots \\
\cdots \\
\cdots\end{array}$ & $\begin{array}{l}\cdots \\
\cdots \\
\cdots\end{array}$ & $\begin{array}{l}\cdots \\
\cdots \\
\cdots\end{array}$ & $\begin{array}{l}\cdots \\
\cdots \\
\cdots\end{array}$ \\
\hline HD 80077 & $\begin{array}{r}2.1 \\
4.1 \\
5.7 \\
32.8\end{array}$ & $\begin{array}{l}2.1 \\
5.1 \\
8.0 \\
9.6\end{array}$ & $\begin{array}{l}1.9 \\
1.1 \\
2.2 \\
2.9\end{array}$ & $\begin{array}{r}1.0 \\
3.6 \\
2.5 \\
10.8\end{array}$ & $\begin{array}{c}0.29 \\
0.70 \\
1.12 \\
11.4\end{array}$ & $\begin{array}{l}2.0 \\
5.0 \\
8.3 \\
9.9\end{array}$ & $\begin{array}{l}1.2 \\
1.0 \\
1.6 \\
2.0\end{array}$ & $\begin{array}{l}0.23 \\
0.69 \\
0.66 \\
5.41\end{array}$ & $\begin{array}{l}- \\
- \\
\overline{1.53}\end{array}$ & $\begin{array}{l}- \\
- \\
\overline{-} \\
9.9\end{array}$ & $\begin{array}{c}- \\
- \\
- \\
1.6\end{array}$ & $\begin{array}{l}\leq 0.09^{a} \\
\leq 0.09^{a} \\
\leq 0.09^{a} \\
0.89\end{array}$ \\
\hline HD 92693 & $\begin{array}{l}2.3 \\
0.7 \\
1.2\end{array}$ & $\begin{array}{r}-25.0 \\
-21.4 \\
25.4\end{array}$ & $\begin{array}{l}2.3 \\
2.5 \\
1.4\end{array}$ & $\begin{array}{l}1.0 \\
0.3 \\
0.8\end{array}$ & $\begin{array}{l}0.14 \\
\ldots \\
0.10\end{array}$ & $\begin{array}{l}-24.9 \\
\ldots \\
26.1\end{array}$ & $\begin{array}{c}3.9 \\
\ldots \\
1.4\end{array}$ & $\begin{array}{c}0.035 \\
\ldots \\
0.067\end{array}$ & $\begin{array}{l}\ldots \\
\ldots \\
\ldots\end{array}$ & $\begin{array}{l}\cdots \\
\cdots \\
\cdots\end{array}$ & $\begin{array}{l}\cdots \\
\ldots \\
\cdots\end{array}$ & $\begin{array}{l}\cdots \\
\cdots \\
\cdots\end{array}$ \\
\hline HD 94413 & 4.6 & 5.1 & 1.2 & 5.1 & 1.63 & 5.1 & 0.8 & 2.02 & 0.12 & 5.1 & 0.4 & 0.30 \\
\hline HD 106391 & 3.6 & -30.3 & 2.8 & 1.2 & 0.42 & -30.0 & 2.6 & 0.16 & $\ldots$ & $\ldots$ & $\cdots$ & $\cdots$ \\
\hline HD 110432 & $\begin{array}{l}0.6 \\
1.9 \\
1.8 \\
8.6\end{array}$ & $\begin{array}{r}-30.9 \\
-26.3 \\
-22.3 \\
5.1\end{array}$ & $\begin{array}{l}1.2 \\
3.8 \\
2.8 \\
4.6\end{array}$ & $\begin{array}{l}0.4 \\
0.5 \\
0.6 \\
1.7\end{array}$ & $\begin{array}{l}- \\
- \\
- \\
1.33\end{array}$ & $\begin{array}{l}- \\
- \\
- \\
5.1\end{array}$ & $\begin{array}{c}- \\
- \\
- \\
3.3\end{array}$ & $\begin{array}{l}\leq 0.023^{a} \\
\leq 0.023^{a} \\
\leq 0.023^{a} \\
0.38\end{array}$ & $\begin{array}{l}- \\
- \\
-\end{array}$ & $\begin{array}{l}- \\
- \\
- \\
-\end{array}$ & $\begin{array}{l}- \\
- \\
- \\
-\end{array}$ & $\begin{array}{l}\leq 0.025^{a} \\
\leq 0.025^{a} \\
\leq 0.025^{a} \\
\leq 0.025^{a}\end{array}$ \\
\hline
\end{tabular}

The second goal of this work concerning the chemistry has recently received considerable attention. Molecules such as CS (Drdla et al. 1989), $\mathrm{H}_{2} \mathrm{CO}$ and $\mathrm{OH}$ (Magnani et al. 1988; Magnani \& Siskind 1990; Großmann et al. 1990; Großmann \& Heithausen 1992; Boden \& Heithausen 1993; Turner 1993a), $\mathrm{NH}_{3}$ (Heithausen et al. 1987; Mebold et al. 1987; Turner 1993b) and $\mathrm{C}_{3} \mathrm{H}_{2}$ (Turner et al. 1989) have been found in a number of high-latitude clouds. In addition, $\mathrm{HCN}$ and $\mathrm{HCO}^{+}$were detected in the translucent part of the Taurus cloud complex towards HD 29647 (Crutcher 1985). These observations have led to conflicting results concerning the molecular abundances. Magnani et al. (1988) inferred high fractional abundances of $\mathrm{CO}, \mathrm{H}_{2} \mathrm{CO}$ and $\mathrm{OH}$ in clouds with low average extinction $\left(A_{V} \approx 0.6 \mathrm{mag}\right.$ ), approaching the abundances commonly found in dark molecular clouds such as TMC- -1 . These findings were supported by the observations of Großmann et al. (1990) and Meyerdierks et al. (1990). In contrast, significantly lower $\mathrm{H}_{2} \mathrm{CO}$ and $\mathrm{OH}$ abun- dances were deduced by Magnani \& Siskind (1990) and Turner et al. (1989). The latter study even found the abundances of these and other molecules at least an order of magnitude below dark cloud values. A similar conclusion was reached by Großmann \& Heithausen (1992) for a dense high-latitude core. In part, these discrepancies may arise from the difficulty of estimating the extinction and total hydrogen column density at the precise location of the observations. Often only an average $A_{V}$ value over the whole cloud is known from star counts, and standard CO conversion factors may not apply locally. Some of the results of Turner et al. (1989) and Großmann \& Heithausen (1992) may apply to clouds with substantially larger total extinctions (of order 5 magnitudes or more) with higher densities and/or exposed to less intense radiation than the typical translucent cloud studied in this work. Turner et al. (1992) and Turner (1993a,b) have recently used models of cloud structure and chemistry to infer abundances of $\mathrm{C}^{18} \mathrm{O}, \mathrm{H}_{2} \mathrm{CO}$, and $\mathrm{NH}_{3}$ 
Table 1. (continued)

\begin{tabular}{|c|c|c|c|c|c|c|c|c|c|c|c|c|}
\hline \multirow[b]{2}{*}{ Star } & \multicolumn{3}{|c|}{${ }^{12} \mathrm{CO}(1-0)$} & \multirow[b]{2}{*}{$\begin{array}{l}T_{A}^{*} \\
\mathrm{~K}\end{array}$} & \multicolumn{3}{|c|}{${ }^{13} \mathrm{CO}(1-0)$} & \multirow[b]{2}{*}{$\begin{array}{l}T_{A}^{*} \\
\mathrm{~K}\end{array}$} & \multicolumn{3}{|c|}{$\mathrm{C}^{18} \mathrm{O}(1-0)$} & \multirow[b]{2}{*}{$\begin{array}{l}T_{A}^{*} \\
\mathrm{~K}\end{array}$} \\
\hline & $\begin{array}{l}\int T_{A}^{*} d V \\
\mathbf{K ~ k m ~ s} ~^{-1}\end{array}$ & $\begin{array}{l}V_{L S R} \\
\mathrm{~km} \mathrm{~s}^{-1}\end{array}$ & $\begin{array}{l}\Delta V \\
\mathrm{~km} \mathrm{~s}^{-1}\end{array}$ & & $\begin{array}{l}\int T_{A}^{*} d V \\
\mathrm{~K} \mathrm{~km} \mathrm{~s}{ }^{-1}\end{array}$ & $\begin{array}{l}V_{L S R} \\
\mathrm{~km} \mathrm{~s}^{-1}\end{array}$ & $\begin{array}{l}\Delta V \\
\mathrm{~km} \mathrm{~s}^{-1}\end{array}$ & & 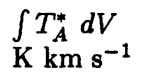 & $\begin{array}{l}V_{L S R} \\
\mathrm{~km} \mathrm{~s}^{-1}\end{array}$ & $\begin{array}{l}\Delta V \\
\mathrm{~km} \mathrm{~s}^{-1}\end{array}$ & \\
\hline$(-5,0)$ & $\begin{array}{r}9.0 \\
12.5\end{array}$ & $\begin{array}{r}-24.7 \\
4.7\end{array}$ & $\begin{array}{l}6.4 \\
5.5\end{array}$ & $\begin{array}{l}1.3 \\
2.1\end{array}$ & $\overline{2} .3$ & $\overline{4} .5$ & $\overline{-}$ & $\begin{array}{l}\leq 0.12^{a} \\
0.67\end{array}$ & $\overline{0.38}$ & $\overline{4.0}$ & 3.7 & $\begin{array}{l}\leq 0.03^{a} \\
0.97\end{array}$ \\
\hline HD 147889 & 22.1 & 2.9 & 2.0 & 10.2 & 2.3 & 3.3 & 1.5 & 1.5 & 0.12 & 3.2 & 1.5 & 0.075 \\
\hline HD 149404 & $\begin{array}{l}4.2 \\
1.5 \\
0.8\end{array}$ & $\begin{array}{r}-8.5 \\
5.3 \\
6.7\end{array}$ & $\begin{array}{l}2.1 \\
0.9 \\
0.9\end{array}$ & $\begin{array}{l}1.9 \\
1.6 \\
0.8\end{array}$ & $\begin{array}{l}0.26 \\
\ldots \\
\cdots\end{array}$ & $\begin{array}{c}-7.6 \\
\ldots \\
\cdots\end{array}$ & $\begin{array}{l}1.7 \\
\ldots \\
\ldots\end{array}$ & $\begin{array}{c}0.15 \\
\cdots \\
\cdots\end{array}$ & $\begin{array}{l}\cdots \\
\cdots \\
\cdots\end{array}$ & $\begin{array}{l}\cdots \\
\cdots \\
\cdots\end{array}$ & $\begin{array}{l}\cdots \\
\cdots \\
\cdots\end{array}$ & $\begin{array}{l}\cdots \\
\ldots \\
\cdots\end{array}$ \\
\hline HD 154368 & $\begin{array}{l}1.8 \\
3.6\end{array}$ & $\begin{array}{l}5.0 \\
5.8\end{array}$ & $\begin{array}{l}0.7 \\
1.0\end{array}$ & $\begin{array}{l}2.6 \\
3.2\end{array}$ & $\begin{array}{l}0.24 \\
0.42\end{array}$ & $\begin{array}{l}5.7 \\
6.4\end{array}$ & $\begin{array}{l}0.6 \\
0.6\end{array}$ & $\begin{array}{l}0.37 \\
0.69\end{array}$ & $\begin{array}{l}\cdots \\
\cdots\end{array}$ & $\begin{array}{l}\ldots \\
\ldots\end{array}$ & $\begin{array}{l}\cdots \\
\cdots\end{array}$ & $\begin{array}{l}\cdots \\
\cdots\end{array}$ \\
\hline HD 156738 & $\begin{array}{l}2.9 \\
2.7\end{array}$ & $\begin{array}{l}5.9 \\
6.6\end{array}$ & $\begin{array}{l}0.7 \\
0.9\end{array}$ & $\begin{array}{l}3.8 \\
2.7\end{array}$ & $\begin{array}{l}\cdots \\
\cdots\end{array}$ & $\begin{array}{l}\cdots \\
\cdots\end{array}$ & $\begin{array}{l}\cdots \\
\cdots\end{array}$ & $\begin{array}{l}\ldots \\
\cdots\end{array}$ & $\begin{array}{l}\cdots \\
\cdots\end{array}$ & $\begin{array}{l}\cdots \\
\cdots\end{array}$ & $\begin{array}{l}\ldots \\
\cdots\end{array}$ & $\begin{array}{l}\ldots \\
\cdots\end{array}$ \\
\hline HD 161056 & 3.0 & -2.5 & 2.2 & 1.2 & ... & $\cdots$ & $\ldots$ & $\ldots$ & $\ldots$ & $\ldots$ & $\ldots$ & $\ldots$ \\
\hline HD 166734 & $\begin{array}{l}1.3 \\
0.3\end{array}$ & $\begin{array}{r}6.1 \\
12.6\end{array}$ & $\begin{array}{l}1.0 \\
1.0\end{array}$ & $\begin{array}{l}1.3 \\
0.3\end{array}$ & - & - & - & $\begin{array}{l}\leq 0.03^{a} \\
\leq 0.03^{a}\end{array}$ & $\begin{array}{l}\ldots \\
\cdots\end{array}$ & $\begin{array}{l}\cdots \\
\cdots\end{array}$ & $\begin{array}{l}\ldots \\
\ldots\end{array}$ & $\begin{array}{l}\cdots \\
\cdots\end{array}$ \\
\hline HD 169454 & $\begin{array}{l}2.9 \\
1.9\end{array}$ & $\begin{array}{l}5.8 \\
6.5\end{array}$ & $\begin{array}{l}0.9 \\
0.7\end{array}$ & $\begin{array}{l}3.0 \\
2.5\end{array}$ & $\begin{array}{l}\ldots \\
0.92\end{array}$ & $\begin{array}{l}\ldots \\
6.3\end{array}$ & $\ddot{0.9}$ & $\begin{array}{c}\ldots \\
0.97\end{array}$ & $\begin{array}{c}\ldots \\
0.02\end{array}$ & 6.0 & 0.5 & 0.04 \\
\hline HD 169754 & 4.2 & 6.9 & 1.0 & $3.9^{b}$ & 0.62 & 6.7 & 0.6 & $0.93^{b}$ & 0.054 & 7.1 & 1.0 & 0.05 \\
\hline BD $-14^{\circ} 5037$ & $\begin{array}{l}2.6 \\
1.7 \\
0.4 \\
0.2\end{array}$ & $\begin{array}{r}8.7 \\
15.3 \\
18.4 \\
24.8\end{array}$ & $\begin{array}{l}1.1 \\
2.7 \\
1.2 \\
0.6\end{array}$ & $\begin{array}{l}2.1 \\
0.6 \\
0.3 \\
0.3\end{array}$ & $\begin{array}{l}0.30 \\
\ldots \\
\ldots \\
\cdots\end{array}$ & $\begin{array}{l}8.7 \\
\cdots \\
\cdots \\
\cdots\end{array}$ & $\begin{array}{c}0.7 \\
\ldots \\
\ldots \\
\ldots\end{array}$ & $\begin{array}{c}0.41 \\
\ldots \\
\ldots \\
\ldots\end{array}$ & $\begin{array}{l}- \\
\cdots \\
\cdots \\
\cdots\end{array}$ & $\begin{array}{l}- \\
\ldots \\
\cdots \\
\cdots\end{array}$ & $\begin{array}{l}- \\
\ldots \\
\ldots \\
\ldots\end{array}$ & $\begin{array}{l}\leq 0.014^{a} \\
\ldots \\
\ldots \\
\ldots\end{array}$ \\
\hline HD 170740 & $\begin{array}{l}6.0 \\
1.2 \\
2.1\end{array}$ & $\begin{array}{r}6.6 \\
8.8 \\
10.3\end{array}$ & $\begin{array}{l}2.2 \\
1.4 \\
2.8\end{array}$ & $\begin{array}{l}2.6 \\
0.9 \\
0.7\end{array}$ & $\begin{array}{l}0.66 \\
\cdots \\
\cdots\end{array}$ & $\begin{array}{l}7.2 \\
\cdots \\
\cdots\end{array}$ & $\begin{array}{c}2.6 \\
\ldots \\
\ldots\end{array}$ & $\begin{array}{l}0.24 \\
\ldots \\
\cdots\end{array}$ & $\begin{array}{l}\ldots \\
\cdots \\
\cdots\end{array}$ & $\begin{array}{l}\ldots \\
\ldots \\
\cdots\end{array}$ & $\begin{array}{l}\cdots \\
\cdots \\
\cdots\end{array}$ & $\begin{array}{l}\cdots \\
\cdots \\
\cdots\end{array}$ \\
\hline HD 182985 & 1.7 & 4.8 & 1.3 & 1.2 & - & - & - & $\leq 0.03$ & $\ldots$ & $\ldots$ & $\ldots$ & $\ldots$ \\
\hline HD 210121 & 3.1 & -6.1 & 2.0 & 1.5 & 0.15 & -6.0 & 1.7 & 0.08 & $\ldots$ & $\ldots$ & $\ldots$ & $\ldots$ \\
\hline HD 219238 & 1.6 & -4.5 & 1.6 & 0.9 & - & - & - & $\leq 0.03$ & $\cdots$ & $\cdots$ & $\ldots$ & $\cdots$ \\
\hline HD 218662 & 1.1 & -8.3 & 1.5 & 0.7 & $\ldots$ & $\ldots$ & $\ldots$ & $\ldots$ & $\ldots$ & $\ldots$ & $\ldots$ & $\ldots$ \\
\hline
\end{tabular}

a RMS of baseline

${ }^{b}$ complex structure. Fit to main component only

in a sample of cirrus-cloud cores. His abundances are comparable to those found in dark clouds, but higher than expected for cirrus clouds in which $\mathrm{NH}_{3}$ and $\mathrm{H}_{2} \mathrm{CO}$ are rapidly photodissociated. The main advantage of the present work is that the reddening towards the background stars is well known, which allows in principal an accurate determination of the foreground total hydrogen column densities. There is, however, no a priori reason why all the observed millimetre emission towards the star arises in the foreground, so that care must still be exercised in determining abundances relative to hydrogen.

In Sect. 2, we discuss details of the observational procedure. In Sect. 3, we present sensitive observations of ${ }^{12} \mathrm{CO},{ }^{13} \mathrm{CO}$ and $\mathrm{C}^{18} \mathrm{O}$ towards the stars. In addition, selected regions were mapped on a $1-2^{\prime}$ grid to determine the extent and kinematic structure of $\mathrm{CO}$, with investigations of the small-scale structure down to $20^{\prime \prime}$. The morphology of the maps is discussed in Sect. 4, together with an estimate of cloud masses and analysis of velocity structure. The observations of other molecules are presented in Sect. 5. The resulting column densities are given in
Sect. 6 and are compared with predictions of existing chemical models.

\section{Observations}

The observations were carried out between 1989 and 1993 with the Swedish-ESO Submillimetre Telescope (SEST) (Booth et al. 1989). A dual polarization Schottky mixer was used as the frontend, with a measured total single sideband noise temperature of $T_{\text {rec }} \approx 300 \mathrm{~K}$. System temperatures were typically 600 $\mathrm{K}$ at $115 \mathrm{GHz}$ and $450 \mathrm{~K}$ at the lower frequencies. The SEST beamwidth at $115 \mathrm{GHz}$ is $43^{\prime \prime}$. The acousto-optical spectrometer (AOS) used as the backend has a bandwidth of $100 \mathrm{MHz}$ and a resolution of $50 \mathrm{kHz}$, corresponding to $0.13 \mathrm{~km} \mathrm{~s}^{-1}$ at 115 $\mathrm{GHz}$ (Zensen 1984). Frequency switching was employed as the observing mode, with a throw of $15 \mathrm{MHz}$ in general. The telluric CO line was monitored carefully to avoid confusion with the interstellar emission. Pointing checks were done regularly. The deviations from the pointing model were of the order of 


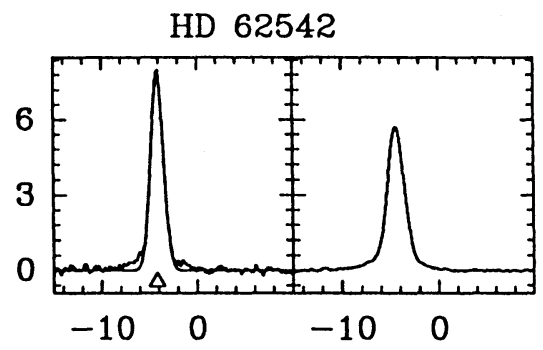

HD 80077

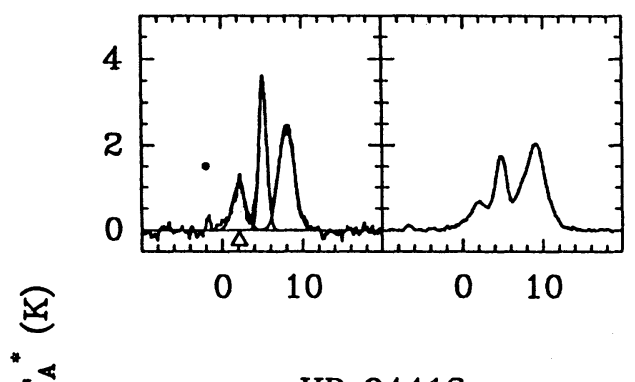

HD 94413

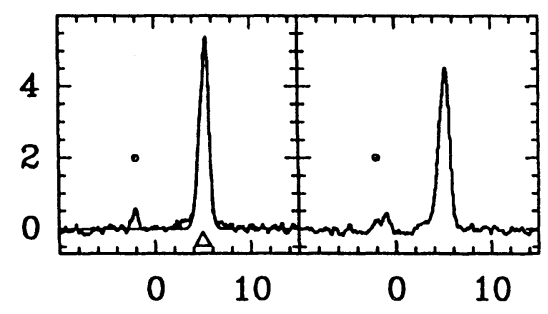

HD 154368

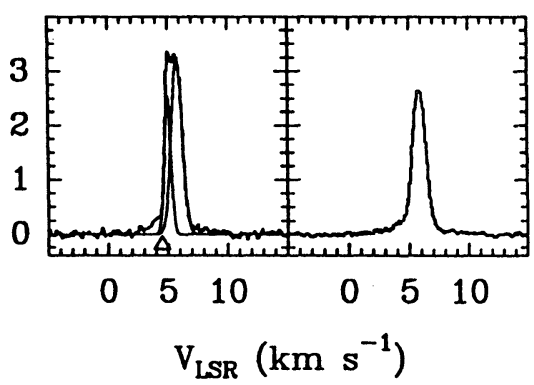

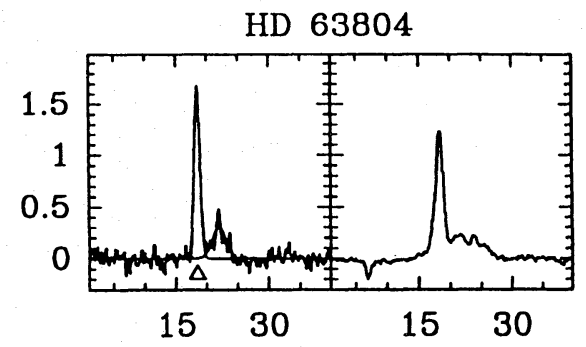

HD 92693

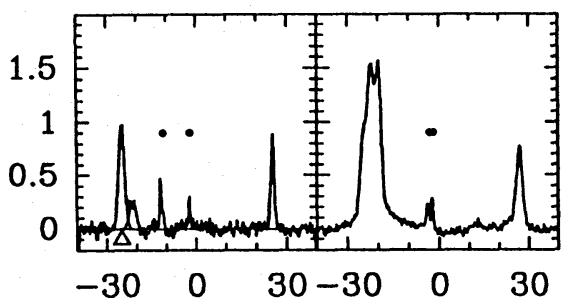

HD 110432

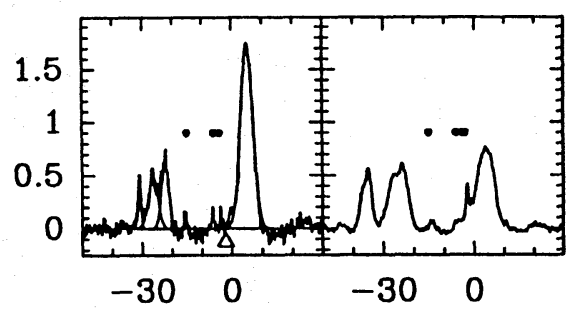

HD 182985

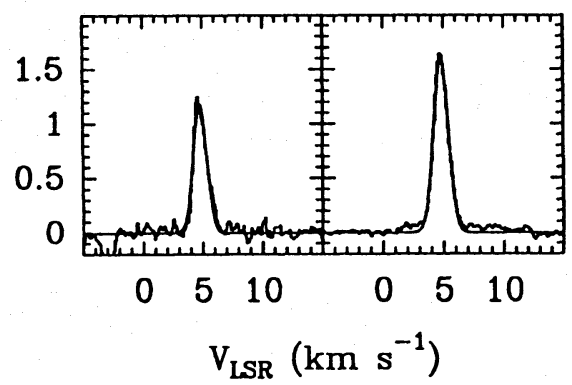

Fig. 1. ${ }^{12} \mathrm{CO}$ line profiles for selected lines of sight. Fits to individual line components are shown. The left hand side of each figure contains the line profile as measured towards the stars together with the corresponding Gaussian fit(s). The spectra shown on the right hand side are the grand average obtained from all data measured around the respective star. Dots identify the telluric $\mathrm{CO}$ line(s). The velocity of the optical absorption lines is indicated by the triangle $5^{\prime \prime}$ RMS. Calibration was achieved through the chopper-wheel method (Kutner \& Ulich 1981). The resulting antenna temperatures $T_{A}^{*}$ were converted into Rayleigh-Jeans brightness temperatures based on the moon efficiency of $\eta_{\text {Moon }}^{*}=0.91$ appropriate for these extended sources. The calibration was occasionally checked by observing Orion A, IRC+10216, and M17SW. The calibration errors are estimated to be of the order of $10 \%-30 \%$.

\section{Results}

\subsection{CO emission towards the stars}

Table 1 summarizes the results of the ${ }^{12} \mathrm{CO},{ }^{13} \mathrm{CO}$ and $\mathrm{C}^{18} \mathrm{O}$ $J=1 \rightarrow 0$ observations towards the individual stars. In cases where no lines were detected, the upper limits on $T_{A}^{*}$ correspond to the $1 \sigma$ noise per resolution element.

A sample of observed ${ }^{12} \mathrm{CO}$ line profiles is shown in Fig. 1. Additional profiles have been published in Gredel et al. (1991) (their Fig. 4). The spectrum on the left-hand side of each figure is the ${ }^{12} \mathrm{CO}$ emission towards the star, whereas that on the right hand side is the grand average obtained by averaging the spectra of the individual map positions. The Gaussian fit(s) to the line profiles are included on the left-hand side. The telluric line is marked by dots and may be found at more than one location when the spectra contain data obtained during several observing sessions. The spectra presented in Fig. 1 range from single, narrow emission lines, such as those towards HD 62542, HD94413, or HD 182985, to multi-component line profiles such 
as those towards HD 92693 and HD 110432. There are regions with multiple $\mathrm{CO}$ emission components which do not vary much relatively across the map (e.g. HD 80077 on $>100^{\prime \prime}$ scales), but also cases where the various $\mathrm{CO}$ profiles change significantly across the map (e.g. HD 110432 on < 1.'5 scales). This point is further discussed in sections 3.2 and 4.2. Table 1 includes the results for ${ }^{13} \mathrm{CO}$ and $\mathrm{C}^{18} \mathrm{O} J=1 \rightarrow 0$ emission. It is seen that in general $\mathrm{C}^{18} \mathrm{O}$ is very weak and is only found for clouds with visual extinctions of $3 \mathrm{mag}$ or more, HD 62542 being the only exception.

In contrast with the optical observations, it is not always obvious which part of the millimetre emission arises from the foreground material, even if the velocity agrees with that of the optical data. Some of the stars observed here are situated at low galactic latitudes, and have emission components at velocities not seen in absorption. In the following, we discard the measurements towards HD 37903 and HD 53367, since they are associated with the reflection nebulae NGC 2023 and IC 2177, respectively. The strong $\mathrm{CO}$ emission towards these stars arises mostly from background material with densities and column densities exceeding those of the foreground translucent clouds. For the other stars which are not obviously associated with reflection nebulae, we assume that the emission at velocities close to those seen in absorption arises from the foreground translucent material.

An important question is the amount of low level emission in the wings of the ${ }^{12} \mathrm{CO}$ lines. One of the original goals of this work was to search for low level wings in the ${ }^{12} \mathrm{CO}$ line profile, as they appear towards other line of sight (e.g. Falgarone \& Phillips 1990). It was originally found that all spectra with high $\mathrm{S} / \mathrm{N}$ show excess emission in the line wings that reaches a few percent of the maximum. An example is shown in Fig. 2 which contains the ${ }^{12} \mathrm{CO}$ spectra towards HD 62542, with Gaussians fitted to the line core. The top spectrum towards HD 62542 was obtained in November 1988; the second in November 1991. The wings seen in the November 1988 spectrum are purely artificial and arise from an instrumental effect which was discussed in some detail by Gredel et al. (1992). During the time of the observations, the phase lock loop (PLL) electronics introduced symmetric line wings with intensities reaching a few percent of that seen in the line center and with an extension of a few km s$~^{-1}$ from the core. The second spectrum towards HD 62542 was measured in November 1991 after modifications to the PLL electronics. Because the wings are absent, we suspect that similar wings seen towards the other stars are artificial as well. We note that our artificial wings towards HD 62542, as well as those towards other stars, have widths that are factors of 3 - 3.6 larger than the width of the ${ }^{12} \mathrm{CO}$ line core, independent of the latter value. It is interesting that these are exactly the characteristics of real line wings discussed for instance by Falgarone \& Phillips (1990).

\section{2. $\mathrm{CO}$ maps}

\subsubsection{HD 62542}

The southern star HD 62542 lies in the direction of the Gum nebula complex towards a region of wind-swept morphology

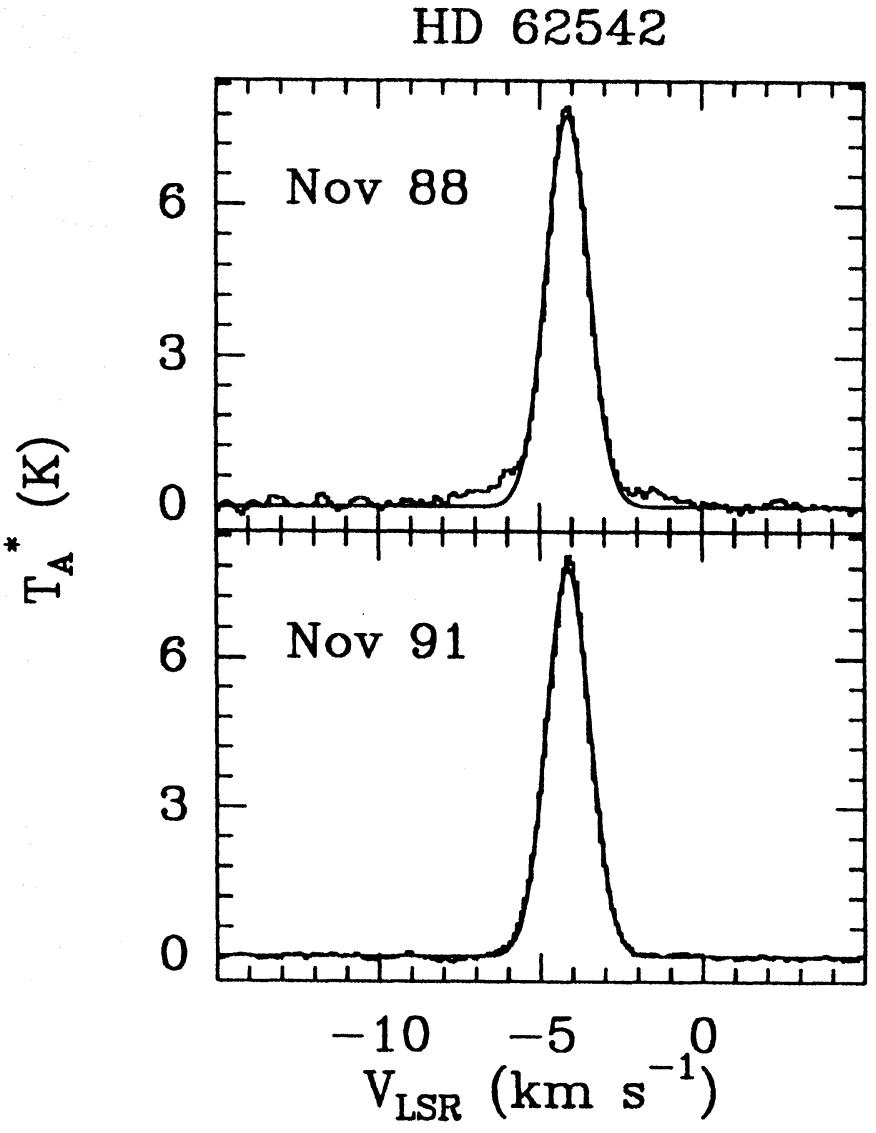

Fig. 2. ${ }^{12} \mathrm{CO}$ line profiles towards HD 62542 obtained in November 1988 and in November 1991. A single Gaussian fitted to the line core is shown. Excess wing emission appearing in the November 1988 spectrum is due to an instrumental effect. The wings are absent in the November 1991 spectrum which was measured after PLL modification.

(cf. Fig. 6 of Cardelli \& Savage 1988). The star is only moderately reddened, $E_{B-V}=0.33 \mathrm{mag}$, but shows strong optical absorption lines of $\mathrm{CH}, \mathrm{CN}$, and $\mathrm{C}_{2}$ (Cardelli et al. 1990; Gredel et al. 1991, 1993). On the other hand, $\mathrm{CH}^{+}$is not detected in this direction despite the large column densities of other species (Cardelli et al. 1990; Gredel et al. 1993). The CO observations of van Dishoeck et al. (1991) suggest rather high densities, of order a few thousand $\mathrm{cm}^{-3}$, and the $\mathrm{C}_{2}$ observations of Gredel et al. (1993) indicate kinetic temperatures around $40 \mathrm{~K}$.

The distribution of the integrated ${ }^{12} \mathrm{CO}$ emission around the star is illustrated in Fig. 3. The position of HD 62542 is indicated by the star, map coordinates are the offsets in arcmin from the stellar position. The grid spacings are $5^{\prime}$ (upper left panel) and $40^{\prime \prime}$ (upper right panel). The beamsize of the SEST is indicated in the upper left corner in both figures by a circle. Contours are 3 (3) $\mathrm{K} \mathrm{km} \mathrm{s}^{-1}$ and 15 (3) $\mathrm{K} \mathrm{km} \mathrm{s}^{-1}$ in the large and small scale maps, respectively, where the first number indicates the lowest contour and the number in parentheses is the increment between adjacent contour lines. Thus, the upper right-hand panel emphasizes only the strongest emission. The elongated, filamentary structure seen on larger scale coincides 
HD 62542
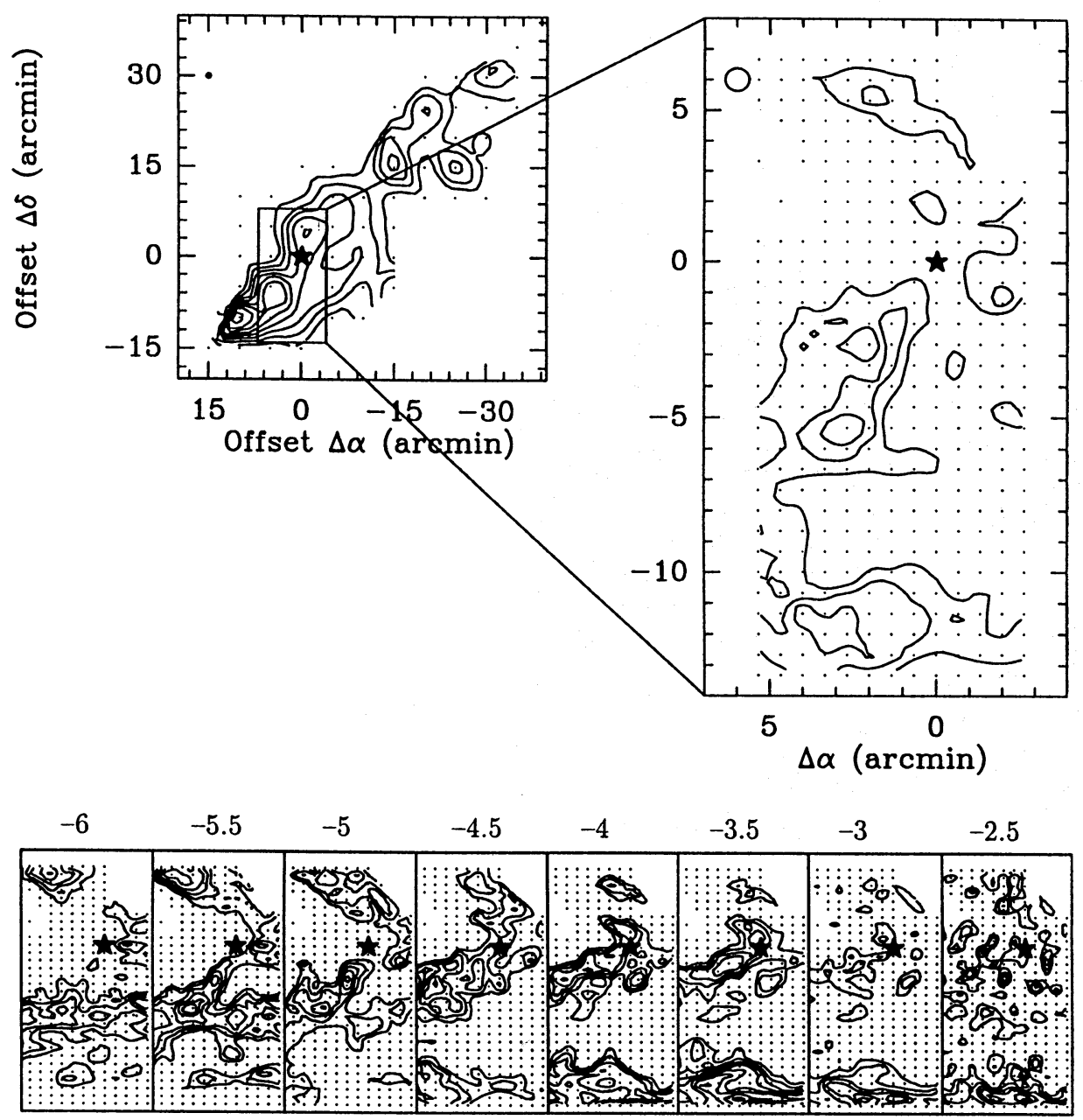

Fig. 3. Map of the integrated ${ }^{12} \mathrm{CO}$ emission towards HD 62542. Map coordinates are offsets from the stellar position indicated by the star. The $(0,0)$ position is indicated by the asterisk. Dots indicate individual map positions. Grid spacings are $5^{\prime}$ (upper left panel) and $40^{\prime \prime}$ (upper right panel). The SEST beam is indicated by a circle. Contours are $3 \mathrm{~K} \mathrm{~km} \mathrm{~s}^{-1}\left(3 \mathrm{~K} \mathrm{~km} \mathrm{~s}^{-1}\right)$ and $15 \mathrm{~K} \mathrm{~km} \mathrm{~s}^{-1}\left(3 \mathrm{~K} \mathrm{~km} \mathrm{~s}^{-1}\right)$ in the large and small scale maps, respectively. Contour steps are given in parentheses. The lower panel shows velocity channel maps constructed from the small scale map. The channel maps cover the same area as the upper right panel. Velocity intervals are $0.5 \mathrm{~km} \mathrm{~s}^{-1}$, the first map shows the emission between $-6 \mathrm{~km} \mathrm{~s}^{-1}$ and $-5.5 \mathrm{~km} \mathrm{~s}^{-1}$. Contour levels are $1(0.5) \mathrm{K} \mathrm{km} \mathrm{s}^{-1}, 3.5(0.5) \mathrm{K} \mathrm{km} \mathrm{s}^{-1}, 3.5(0.5) \mathrm{K} \mathrm{km} \mathrm{s}^{-1}, 3.5(0.5) \mathrm{K} \mathrm{km} \mathrm{s}^{-1}, 2.5$ (0.5) $\mathrm{K} \mathrm{km} \mathrm{s}^{-1}, 1(0.5) \mathrm{K} \mathrm{km} \mathrm{s}^{-1}, 0.5(0.5) \mathrm{K} \mathrm{km} \mathrm{s}^{-1}$, and $0.2(0.2) \mathrm{K} \mathrm{km} \mathrm{s}^{-1}$, respectively

well with the structure of the $\mathrm{H} \alpha$ emission in this region (e.g. Cardelli \& Savage 1988). A superior photograph published recently by O'Donnell et al. (1992) shows even more clearly the striking correspondence between the molecular cloud boundary outlined in $\mathrm{CO}$ emission and the structure of the visible nebulosity. O'Donnell et al. (1992) also present an IRAS SKYFLUX map of $60 \mu \mathrm{m}$ emission in which the peak brightness coincides with the most intense $\mathrm{CO}$ emission in the SE corner of the map (Fig. 3, upper right panel). The ${ }^{12} \mathrm{CO}$ emission arises in a single narrow line with a Gaussian line shape at $V_{L S R}=-4 \mathrm{~km}$ $\mathrm{s}^{-1}$ (cf. Fig. 1). The velocity agrees with that of the optical absorption lines. The line width does not vary significantly across the mapped region, nor is there a significant velocity gradient present. This is illustrated by the eight velocity channel maps constructed from the small scale map and displayed as the bot- tom panel in Fig. 3. The velocity intervals range from $(-6,-5.5)$ $\mathrm{km} \mathrm{s}^{-1}$ to $(-2.5,-2) \mathrm{km} \mathrm{s}^{-1}$ in steps of $0.5 \mathrm{~km} \mathrm{~s}^{-1}$. Although the $\mathrm{CO}$ map shows considerable structure in this region, the dynamic range is not large: for example, the integrated intensity at the highest peak is only twice that in the direction of HD 62542.

\subsubsection{HD 80077}

HD 80077 is a superluminous hypergiant (spectral class $\mathrm{B}_{21} \mathrm{Ia}^{+}$) at a distance of $D \approx 3000 \mathrm{pc}$ and located in the field of Pismis 11. It has a significant reddening of $E_{B-V}=1.52 \mathrm{mag}$ and shows strong absorption lines of $\mathrm{CH}, \mathrm{CH}^{+}, \mathrm{CN}$, and $\mathrm{C}_{2}$. The density and temperature inferred from $\mathrm{C}_{2}$ are lower than towards HD 62542, with values of $n \approx 250 \mathrm{~cm}^{-3}$ and $T \approx 25$ K (van Dishoeck \& Black 1989). 
HD 80077
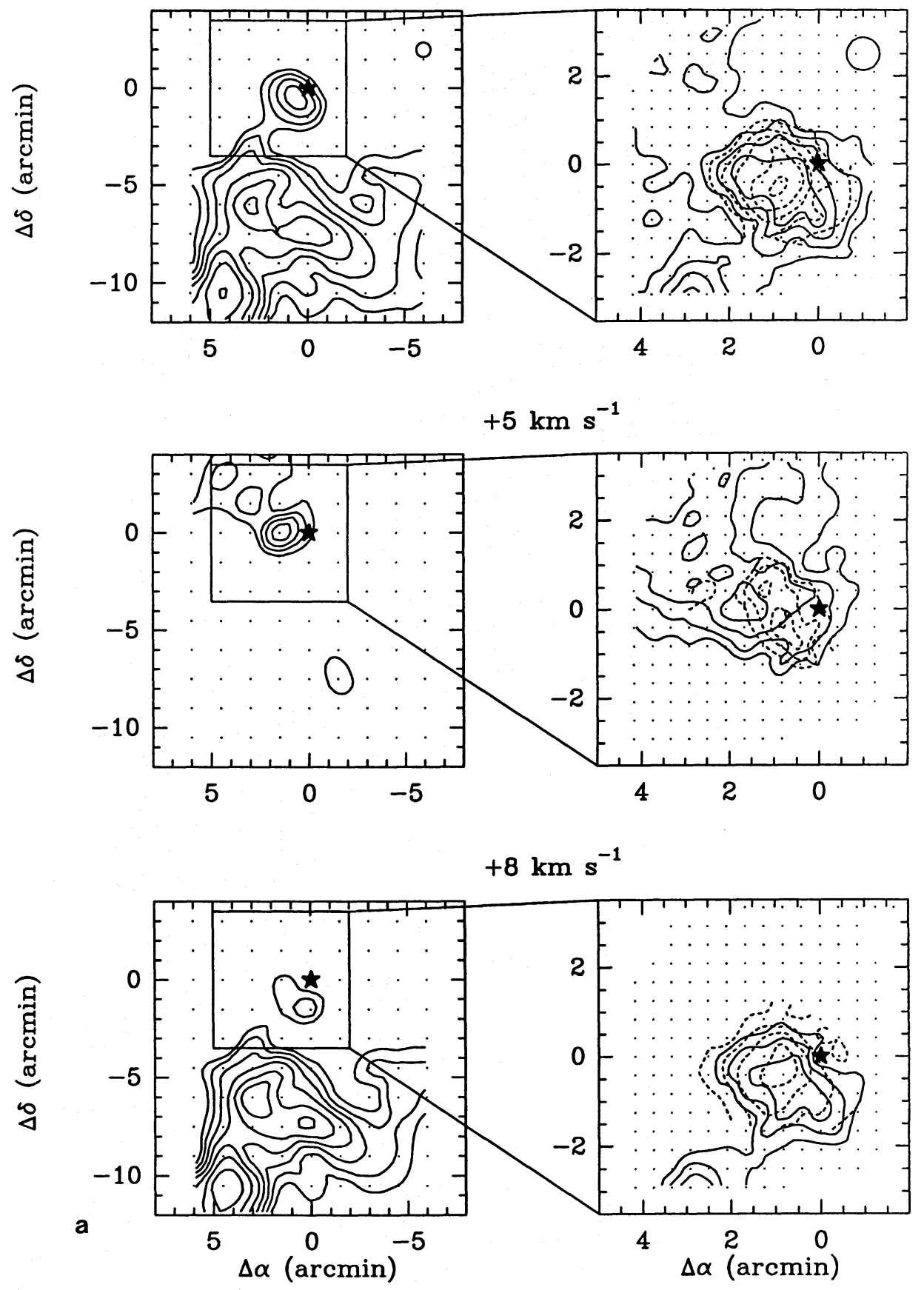

Fig. 4a. Maps of the ${ }^{12} \mathrm{CO}$ and ${ }^{13} \mathrm{CO}$ emission towards HD 80077. Map spacings are 1.5 (left) and $25^{\prime \prime}$ (right). Top pair display $\int T_{A}^{*} d V$ integrated over all velocities, with ${ }^{12} \mathrm{CO}$ contours of $10 \mathrm{~K} \mathrm{~km} \mathrm{~s}^{-1}\left(5 \mathrm{~K} \mathrm{~km} \mathrm{~s}^{-1}\right)$. Middle and bottom pairs show $\int T_{A}^{*} d V$ of the $+5 \mathrm{~km} \mathrm{~s}^{-1}$ and $+8 \mathrm{~km}$ $\mathrm{s}^{-1}$ emission components (cf. Fig. 1). ${ }^{12} \mathrm{CO}$ Contours are $4 \mathrm{~K} \mathrm{~km} \mathrm{~s}^{-1}\left(1 \mathrm{~K} \mathrm{~km} \mathrm{~s}^{-1}\right)$ and $10 \mathrm{~K} \mathrm{~km} \mathrm{~s}^{-1}\left(4 \mathrm{~K} \mathrm{~km} \mathrm{~s}^{-1}\right)$ in the $+5 \mathrm{~km} \mathrm{~s}^{-1}$ and $+8 \mathrm{~km} \mathrm{~s}^{-1}$ channel maps, respectively. The ${ }^{13} \mathrm{CO}$ emission is represented by dashed lines in the small scale maps. Contour levels are $0.7 \mathrm{~K} \mathrm{~km}$ $\mathrm{s}^{-1}\left(0.2 \mathrm{~K} \mathrm{~km} \mathrm{~s}^{-1}\right)$ and $1 \mathrm{~K} \mathrm{~km} \mathrm{~s}^{-1}\left(1 \mathrm{~K} \mathrm{~km} \mathrm{~s}^{-1}\right)$ for the $+5 \mathrm{~km} \mathrm{~s}^{-1}$ and $+8 \mathrm{~km} \mathrm{~s}^{-1}$ components, respectively, and $2 \mathrm{~K} \mathrm{~km} \mathrm{~s}^{-1}\left(1 \mathrm{~K} \mathrm{~km} \mathrm{~s}^{-1}\right)$ in the top panel. The SEST beam is indicated by a circle in the right-hand corner in the upper panels 


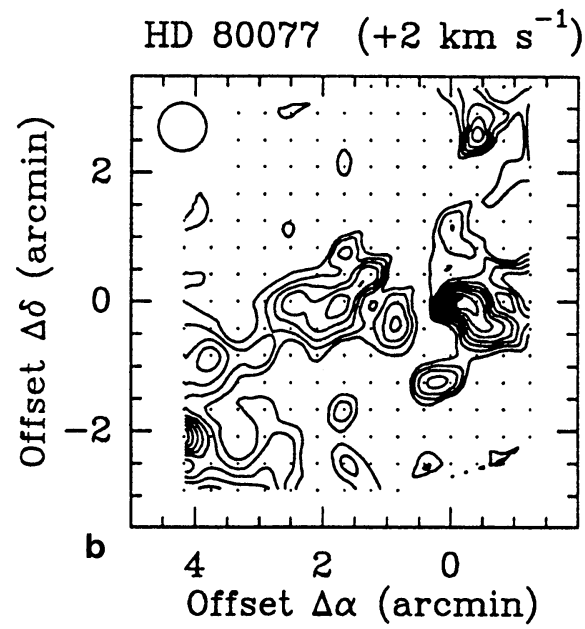

Fig. 4b. Map of the integrated ${ }^{12} \mathrm{CO}$ emission in the $+2 \mathrm{~km} \mathrm{~s}^{-1}$ component (cf. Fig. 1) towards HD 80077, corresponding to the velocity of the optical absorption lines. Contour levels are $0.6(0.3) \mathrm{K} \mathrm{km} \mathrm{s}^{-1}$

The ${ }^{12} \mathrm{CO}$ and ${ }^{13} \mathrm{CO}$ profiles show multiple components with emission at velocities ranging from +2 to $+10 \mathrm{~km} \mathrm{~s}^{-1}$. The three pairs of figures shown in Fig. 4a contain maps of the total $\mathrm{CO}$ intensity integrated over all velocities (top), and maps of the intensities in the $+5 \mathrm{~km} \mathrm{~s}^{-1}$ and $+8 \mathrm{~km} \mathrm{~s}^{-1}$ velocity components (cf. Fig. 1). Grid spacings are 1.5 (left figures) and 25" (right figures). The emission in the $+5 \mathrm{~km} \mathrm{~s}^{-1}$ component shows a local maximum close to the star. Most of the emission is constrained to a small region of about $2^{\prime} \times 2^{\prime}$ extent. The stronger component at $+8 \mathrm{~km} \mathrm{~s}^{-1}$ appears at all observed positions. It also reaches a local maximum close to the star but increases significantly to the south. Neither of these two components is seen in absorption, however. A third, well resolved emission component appears near $+2 \mathrm{~km} \mathrm{~s}^{-1}$, which is where the optical lines are observed. Its distribution in the $7^{\prime} \times 7^{\prime}$ region around HD 80077 is shown in Fig. 4b. The emission is significantly weaker than in the +5 $\mathrm{km} \mathrm{s}^{-1}$ and $+8 \mathrm{~km} \mathrm{~s}^{-1}$ components, and inaccuracies in the baseline subtraction due to the nearby strong components may have affected the absolute intensities. Some artificial structure may therefore be present in the latter map. It can nevertheless be seen that the emission in the $+2 \mathrm{~km} \mathrm{~s}^{-1}$ component has a local maximum around the star, similar to the $+5 \mathrm{~km} \mathrm{~s}^{-1}$ and $+8 \mathrm{~km} \mathrm{~s}^{-1}$ components.

In addition to ${ }^{12} \mathrm{CO}$, the ${ }^{13} \mathrm{CO} J=1 \rightarrow 0$ line was observed with a grid spacing of $25^{\prime \prime}$ around the star. The respective ${ }^{13} \mathrm{CO}$ contours are shown in Fig. 4a by dashed lines. The extent of the ${ }^{13} \mathrm{CO}$ emission is smaller than that of ${ }^{12} \mathrm{CO}$, but their local maxima agree. The ${ }^{13} \mathrm{CO}$ emission from the $+2 \mathrm{~km} \mathrm{~s}^{-1}$ component was too weak to map. The small scale structure of the ${ }^{13} \mathrm{CO}$ emission is further illustrated in Fig. 5 which contains the individual ${ }^{13} \mathrm{CO}$ spectra. It is seen that the ${ }^{13} \mathrm{CO}$ line profile is remarkably self-similar across the map. This behavior would not be expected if the three velocity components arise in spatially well separated clouds, such as found toward HD 110432 (see below). Thus it may be that most of the emission observed towards the star arises in associated sheets or shells such that only one component lies between us and the star. It has also been suggested that such emitting components might originate in twisted filaments whose velocity structure and spatial distribution are dictated by the viewing geometry (e.g. Verschuur 1991).

\subsubsection{HD 182985}

Fig. 6 contains a contour plot of the ${ }^{12} \mathrm{CO}$ emission towards the high-latitude star HD 182985 at 45" spacing. De Vries \& van Dishoeck (1988, unpublished results) have previously detected $\mathrm{CH}, \mathrm{CH}^{+}$and $\mathrm{CN}$ absorption lines towards this star. Contour levels are 4 (1) $\mathrm{K} \mathrm{km} \mathrm{s}^{-1}$ and emphasize the stronger emission. There are two spatially separated emission maxima which are embedded in low level emission with antenna temperatures of 1 $2 \mathrm{~K}$. The low level emission is present at all observed positions. In contrast with the high-latitude cloud towards HD 210121 (Gredel et al. 1992), there is some evidence for a velocity gradient across the cloud. Fig. 6 contains velocity channel maps which indicate that there may be a large-scale rotation (or shear) around a NE - SW axis.

The vicinity around HD 182985 was mapped at higher spatial resolution in ${ }^{12} \mathrm{CO}$ with a grid spacing of $20^{\prime \prime}$ and an integration time per position of $6 \mathrm{~min}$. The resulting baseline rms is $\leq 0.1 \mathrm{~K}$ per channel. Fig. 7 contains a mosaic of the spectra. Note that in general the profiles are simple with a nearly Gaussian shape. The corresponding contour map is shown in Fig. 8. The emission towards HD 182985 appears to vary somewhat on scales of $20^{\prime \prime}$. Fig. 8 contains the velocity channel maps constructed from the high $\mathrm{S} / \mathrm{N}$ spectra. The corresponding velocity intervals are indicated in the headers. No significant velocity gradient is observed in this smaller region.

It is of interest to compare the HD 182985 high-latitude cloud with that towards HD 210121. Both clouds appear very similar in their abundances, although the column densities of $\mathrm{CH}, \mathrm{CN}$, and $\mathrm{CO}$ are a factor of two lower in the HD 182985 cloud. The $\mathrm{CH}^{+}$absorption is weak in both cases.

\subsubsection{Other lines of sight}

The regions around HD 63804, HD 92693, HD 110432, and HD 154368 were mapped in ${ }^{12} \mathrm{CO}$ with grid spacings between $40^{\prime \prime}$ and $2^{\prime}$. The four maps are shown in Fig. 9. HD 154368 lies in the Galactic plane and shows strong molecular absorption lines of $\mathrm{CH}, \mathrm{C}_{2}$ and $\mathrm{CN}$. From $\mathrm{C}_{2}$ observations, van Dishoeck $\&$ de Zeeuw (1984) inferred densities around $250 \mathrm{~cm}^{-3}$ and temperatures around $25 \mathrm{~K} . \mathrm{CH}^{+}$, on the other hand, is relatively weak (Gredel et al. 1993). The velocity of the ${ }^{12} \mathrm{CO}$ emission seen towards HD 154368 agrees with that of the optical absorption lines. The map shown here contains the integrated ${ }^{12} \mathrm{CO}$ emission, with contour levels of 3 (1) $\mathrm{K} \mathrm{km} \mathrm{s}^{-1}$. The lowest contour corresponds to approximately $50 \%$ of maximum. At the map spacing of $2^{\prime}$, the ${ }^{12} \mathrm{CO}$ emission is remarkably uniform.

In contrast, the emission towards HD 63804, HD 92693, and HD 110432 is characterized by complex CO line profiles (cf. Fig. 1) which vary on scales of a few arcmin. All three directions show additional emission components with no opti- 


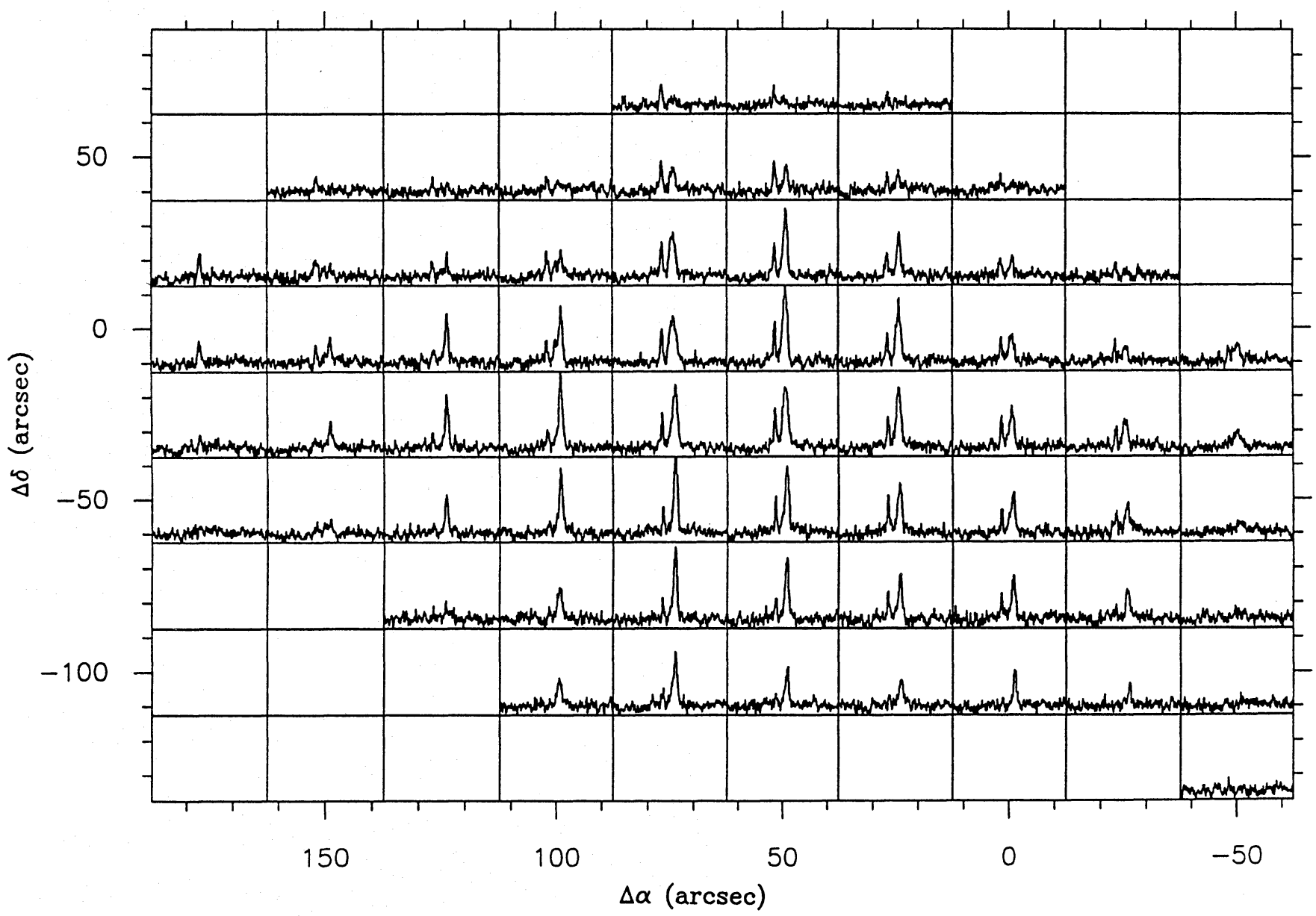

Fig. 5. Mosaic of the ${ }^{13} \mathrm{CO}$ line profiles obtained with a grid of $25^{\prime \prime}$ around HD 80077. Each spectrum is shown with $-10 \mathrm{~km} \mathrm{~s}{ }^{-1}<V_{L S R}<$ $+25 \mathrm{~km} \mathrm{~s}^{-1}$ and $-0.3 \mathrm{~K}<T_{A}^{*}<2.5 \mathrm{~K}$

cal counterparts (cf. Fig. 1). In the following, we focus on the distribution of the ${ }^{12} \mathrm{CO}$ emission components whose velocities agree with those of the optical absorption lines. HD 63804 is a member of NGC 2439 and is significantly reddened. The foreground material contains large column densities of $\mathrm{CH}, \mathrm{CH}^{+}$, $\mathrm{CN}$, and $\mathrm{C}_{2}$ (Gredel et al. 1993). The map towards HD 63804 shows the ${ }^{12} \mathrm{CO}$ component between +16 and $+20 \mathrm{~km} \mathrm{~s}^{-1}$. The emission is relatively weak towards the star and increases by about a factor of two in the south-east.

HD 92693 is located in the Car OB1 association. It is significantly reddened but the interstellar absorption lines are not strong, and $\mathrm{C}_{2}$ is only marginally detected (Gredel \& Münch 1986; Gredel et al. 1993). The star is distant $(2500 \mathrm{pc})$ and probably reddened by a large column of low-density, diffuse material (Gredel \& Münch 1986). The ${ }^{12} \mathrm{CO}$ emission towards HD 92693 in the $-25 \mathrm{~km} \mathrm{~s}^{-1}$ component is relatively weak, and its extent is shown in Fig. 9. The region is characterized by low level emission towards the star, with strong emission peaks to the south and north of the star.

HD 110432 lies in the direction of the Southern Coalsack, which was mapped in ${ }^{12} \mathrm{CO}$ by Nyman et al. (1989) with a sampling of $8^{\prime}$. The star sits at the edge of an elongated region of strong CO emission with an extent of approximately $20^{\prime} \times 40^{\prime}$ (see the map of Nyman et al. 1989). The map shown in Fig. 9 was obtained with a grid spacing of 1.5 and contains the integrated emission in the $+5 \mathrm{~km} \mathrm{~s}^{-1}$ component. Contours are 3 (3) $\mathrm{K} \mathrm{km}$ $\mathrm{s}^{-1}$. The optical absorption lines appear at velocities between -2 and $+1.5 \mathrm{~km} \mathrm{~s}^{-1}$, which is closest to the broad $+5 \mathrm{~km} \mathrm{~s}^{-1}$ component. The complexity of the $\mathrm{CO}$ emission is illustrated in Fig. 10. The emission changes on spatial scales of less than $1^{\prime}$, which corresponds to about $0.05 \mathrm{pc}$ at the distance of the Coalsack. Note however that the Coalsack lies in the galactic plane, and much of the emission seen here may arise from the background.

\subsection{Emission from other molecules}

Emission from various molecules was searched towards a few stars which show strong $\mathrm{CO}$ emission, and for which we can be fairly certain that most of the emitting material is located in front of the star (e.g. HD 62542, HD 169454, HD 154368). The results are summarized in Table 2 . In case of non-detections, the listed antenna temperatures correspond to $1 \sigma \mathrm{rms}$ noise per velocity channel. The $\mathrm{CN}$ observations were already presented in Gredel et al. (1991). Molecules such as $\mathrm{HCN}, \mathrm{HCO}^{+}, \mathrm{CS}$, and $\mathrm{CN}$ were 

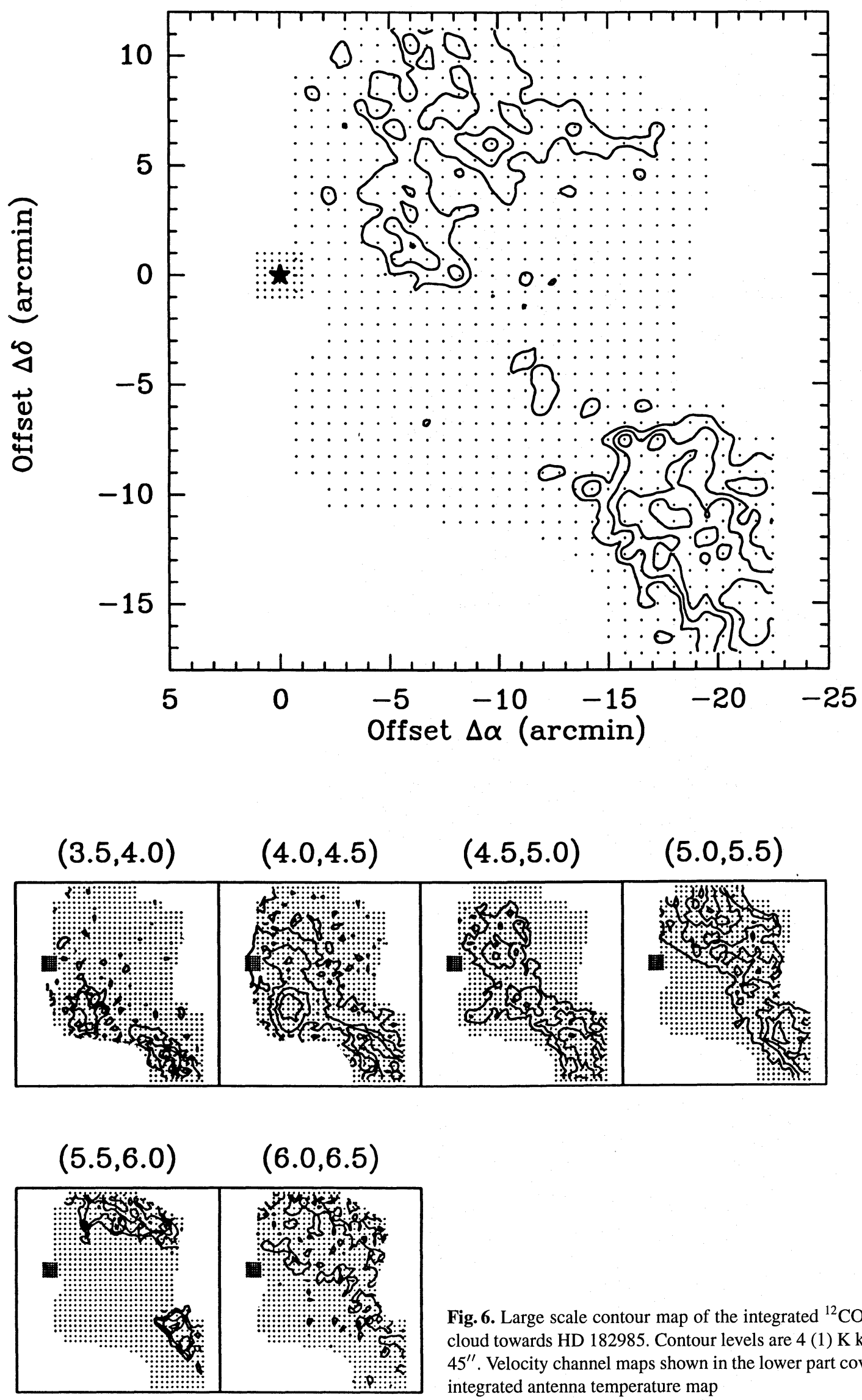

Fig. 6. Large scale contour map of the integrated ${ }^{12} \mathrm{CO}$ emission of the high-latitude cloud towards HD 182985. Contour levels are 4 (1) $\mathrm{K} \mathrm{km} \mathrm{s}^{-1}$, map grid spacings are $45^{\prime \prime}$. Velocity channel maps shown in the lower part cover the same region as the total integrated antenna temperature map 


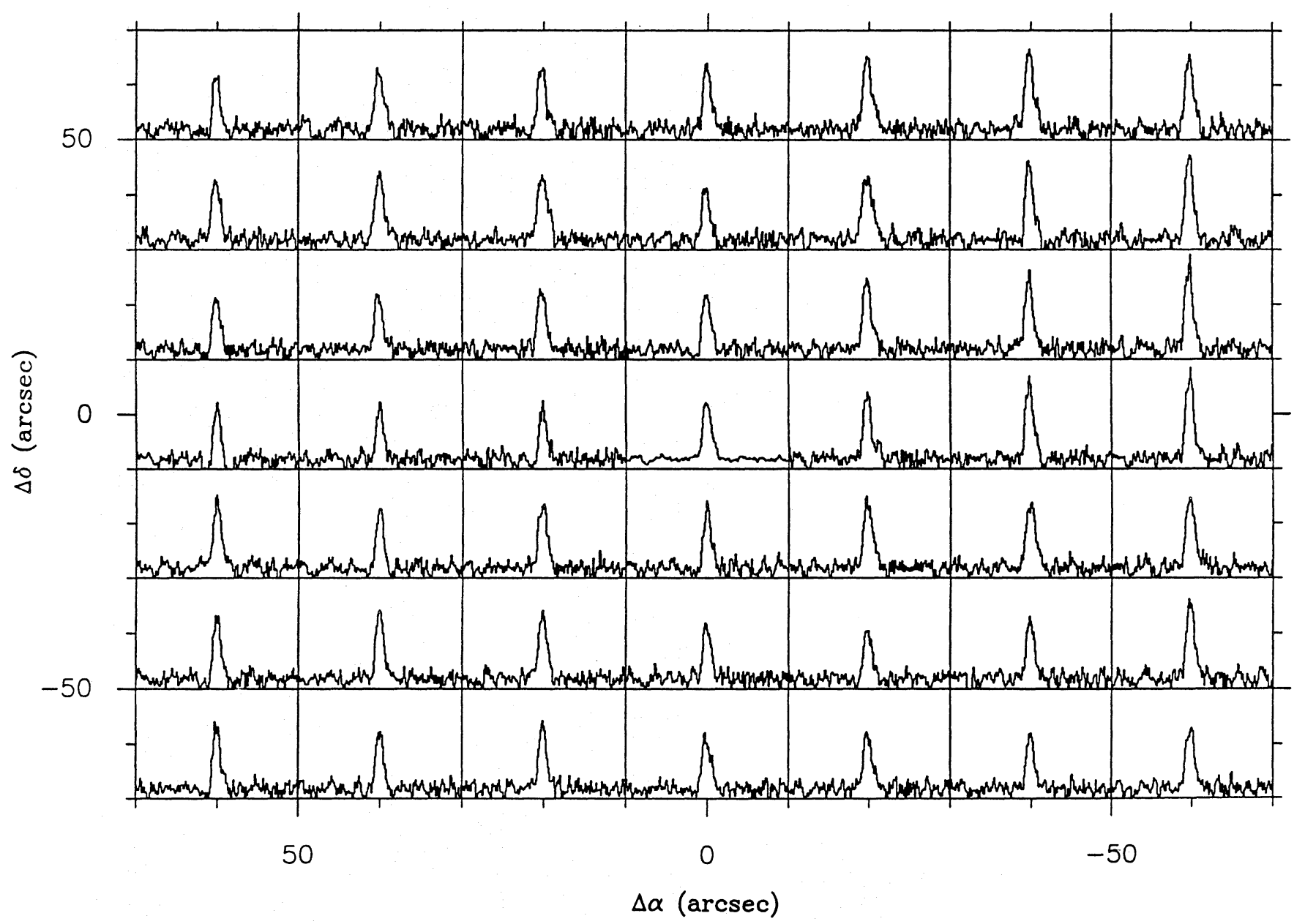

Fig. 7. Mosaic showing the small scale structure of ${ }^{12} \mathrm{CO}$ around HD 182985 . Each spectrum is shown at a scale of $-5 \mathrm{~km} \mathrm{~s}{ }^{-1}<V_{L S R}<15$ $\mathrm{km} \mathrm{s}^{-1}$ and $-0.2<T_{A}^{*}<2 \mathrm{~K}$. The baseline rms is $0.1 \mathrm{~K}$ per channel

detected towards a few stars. In general, the emission occurs at velocities close to those of the absorption lines. An exception is $\mathrm{HD} 80077$, where $\mathrm{HCO}^{+}$was detected only in the strongest $+8 \mathrm{~km} \mathrm{~s}^{-1}$ component, but not in the $+2 \mathrm{~km} \mathrm{~s}^{-1}$ component corresponding to the absorption lines. The spectrum of $\mathrm{C}_{2} \mathrm{H}$ towards HD 169454, a line of sight with a large column density of molecular carbon, shows a possible $2 \sigma$ feature at the velocity of the absorption lines, but this is listed as an upper limit in the Table. $\mathrm{C}_{3} \mathrm{H}_{2}$ was searched towards HD 29647 and HD 62542, two sightlines with large molecular column densities, but not detected. As an example, the $\mathrm{HCO}^{+}, \mathrm{CS}$, and $\mathrm{HCN}$ spectra towards HD 62542 are shown in Fig. 11. In the right-hand side of this figure, the ${ }^{12} \mathrm{CO},{ }^{13} \mathrm{CO}$, and $\mathrm{C}^{18} \mathrm{O}$ profiles measured at an offset of $\left(4 ! 7,6^{\prime}\right)$ from the star are shown as well. The latter three spectra are all drawn at the same scale.

\section{Discussion}

\subsection{Line ratios}

The ratio of the ${ }^{12} \mathrm{CO}$ and ${ }^{13} \mathrm{CO}$ antenna temperatures of our sample of translucent clouds is plotted versus $T_{A}^{*}\left({ }^{12} \mathrm{CO}\right)$ in Fig. 12. A significant increase occurs if $T_{A}^{*}\left({ }^{12} \mathrm{CO}\right)<3 \mathrm{~K}$. A similar variation was found from comparison of ${ }^{12} \mathrm{CO}$ and ${ }^{13} \mathrm{CO}$ emission at various positions within a single translucent cloud, i.e. the cloud towards HD 210121 (Gredel et al. 1992; see also Stark 1993). As discussed in those papers, the variation arises primarily because the ${ }^{12} \mathrm{CO}$ millimetre lines become optically thick, whereas those of ${ }^{13} \mathrm{CO}$ remain optically thin. The average of all measurements presented here is $T_{A}^{*}\left({ }^{12} \mathrm{CO}\right) / T_{A}^{*}\left({ }^{13} \mathrm{CO}\right)$ $=6.2 \pm 5.5$ but reaches values $>20$ for the most diffuse clouds. A similar value has been determined by Polk et al. (1988) who found $6.7 \pm 0.7$ for a large-scale average of diffuse and dense material in the Galactic plane. By this measure of 'thickness' in $\mathrm{CO}$ lines, most of the clouds in our sample are thinner than any of the clouds in the sample of Turner et al. (1992), where 

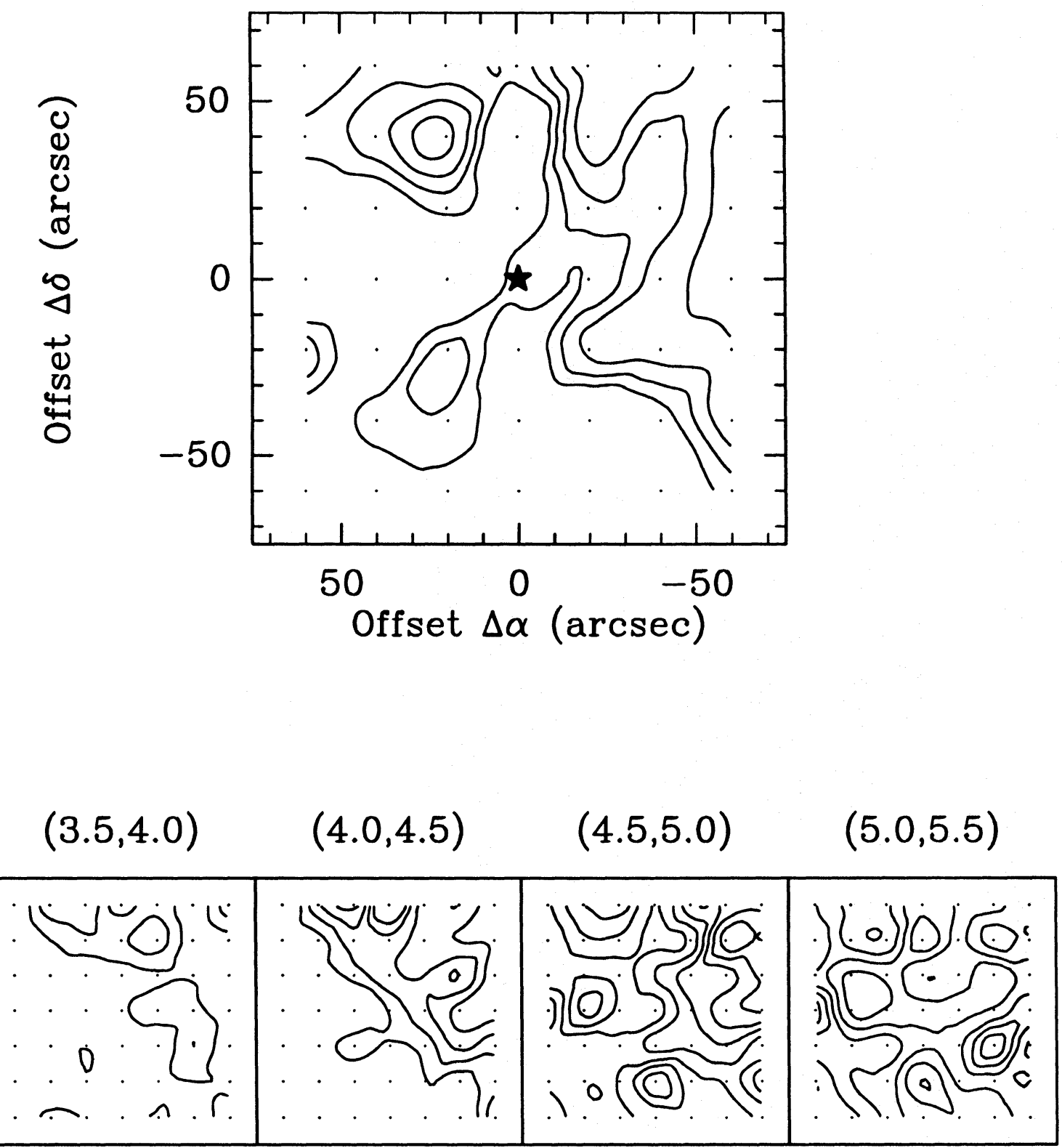

\section{$(5.5,6.0) \quad(6.0,6.5)$}

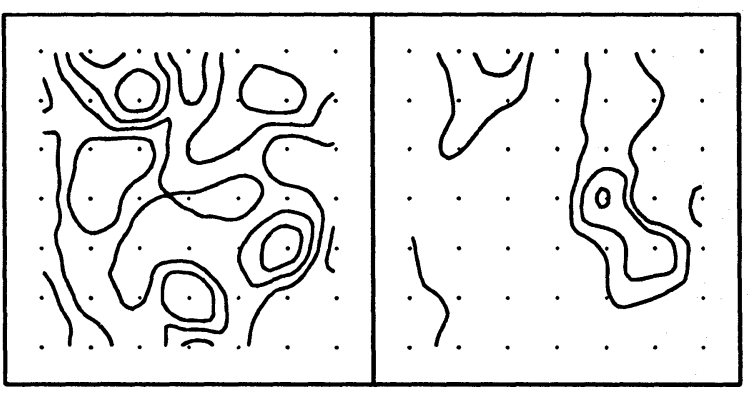

Fig. 8. Contour diagram of integrated emission and velocity channel maps in the direction of HD 182985. Contours are $1.5(0.15) \mathrm{K} \mathrm{km} \mathrm{s}^{-1}$, map grid spacings are $20^{\prime \prime}$. Offsets are in arcsec from the stellar position. Channel maps cover the same region as the $\int T_{A}^{*} d V$ map 


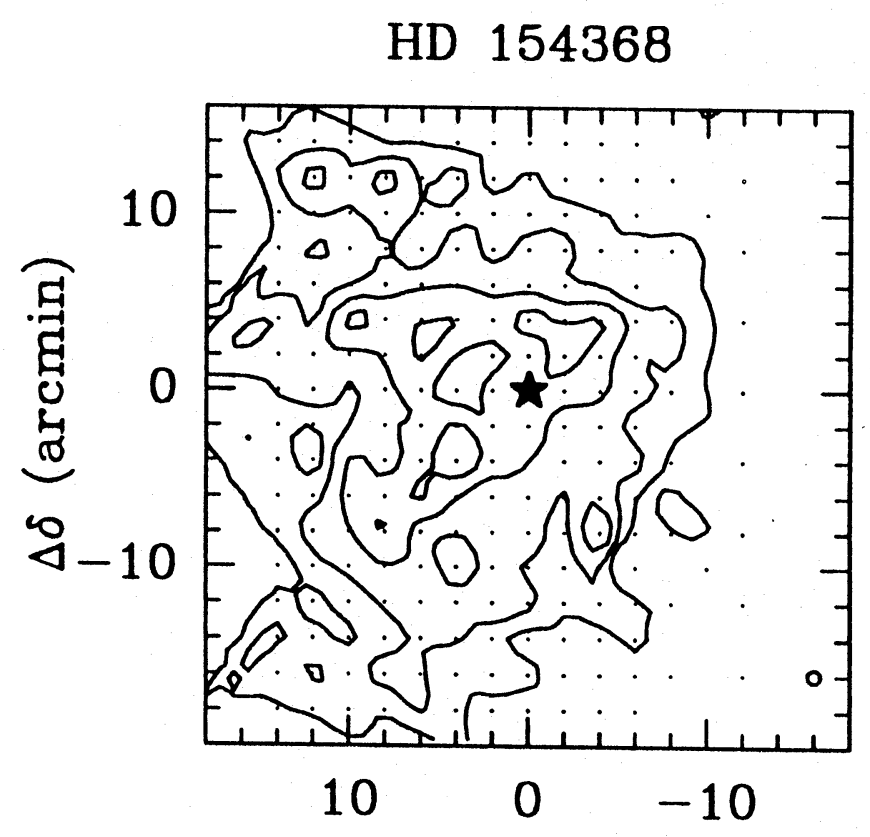

HD 92693

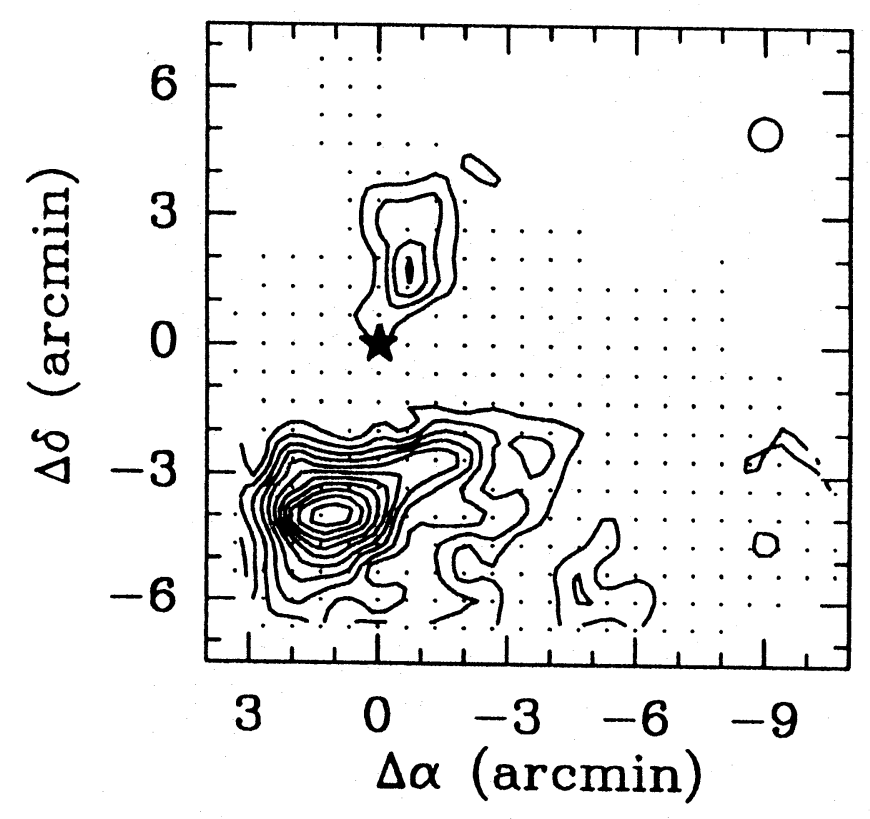

HD 63804

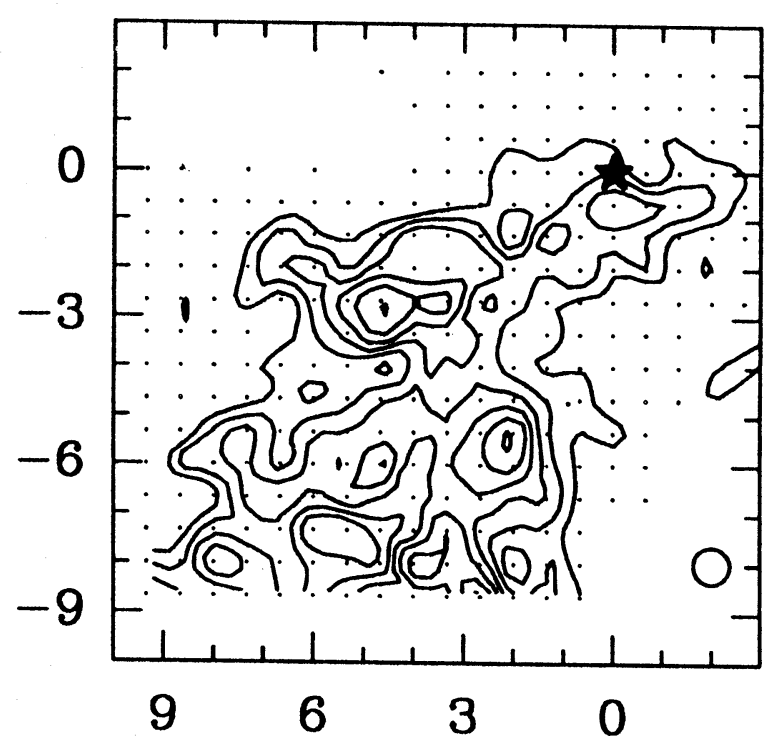

HD 110432

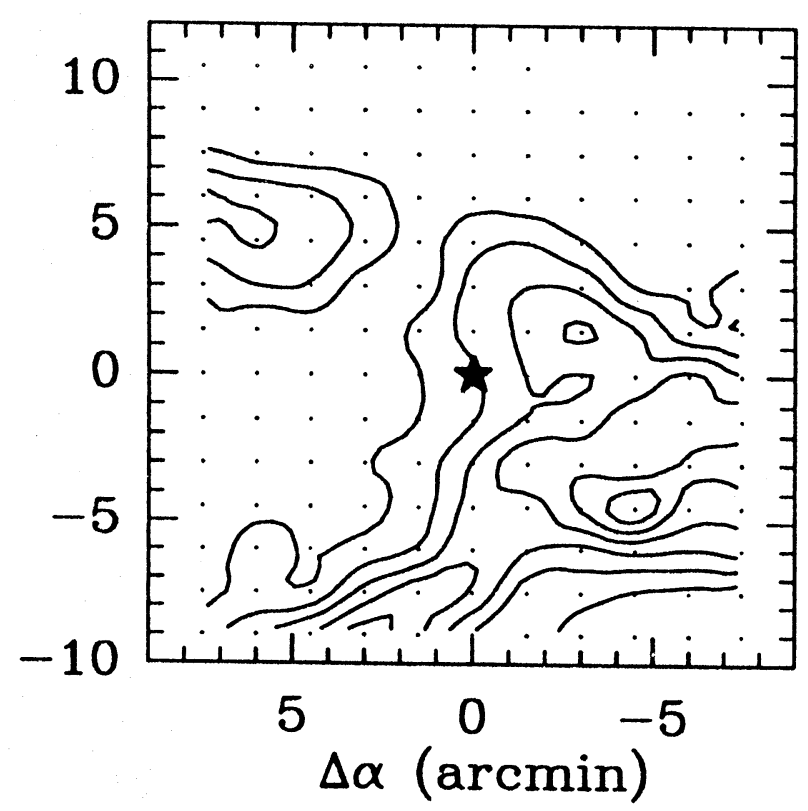

Fig. 9. Contour maps of integrated emission $\int T_{A}^{*} d V$ for various lines of sight. In the HD 154368 map (grid spacing $2^{\prime}$ ), contour levels are 3 (1) $\mathrm{K} \mathrm{km} \mathrm{s}^{-1}$. The HD 63804 map (grid spacing $40^{\prime \prime}$ ) contains the emission in the $+16-+20 \mathrm{~km} \mathrm{~s}^{-1}$ velocity interval, corresponding to the velocity of the optical absorption lines, with contours of $2(0.5) \mathrm{K} \mathrm{km} \mathrm{s}^{-1}$. Towards HD 92693 (grid spacing 40"), the emission in the -22 $-27 \mathrm{~km} \mathrm{~s}^{-1}$ (contours 2 (2) $\mathrm{K} \mathrm{km} \mathrm{s}^{-1}$ ) are shown. The contour levels in the HD 110432 diagram (grid spacing $\left.1 . .^{\prime} 5\right)$ are $3(3) \mathrm{K} \mathrm{km} \mathrm{s}^{-1}$ and show the emission in the $-1-+11 \mathrm{~km} \mathrm{~s}^{-1}$ velocity interval 


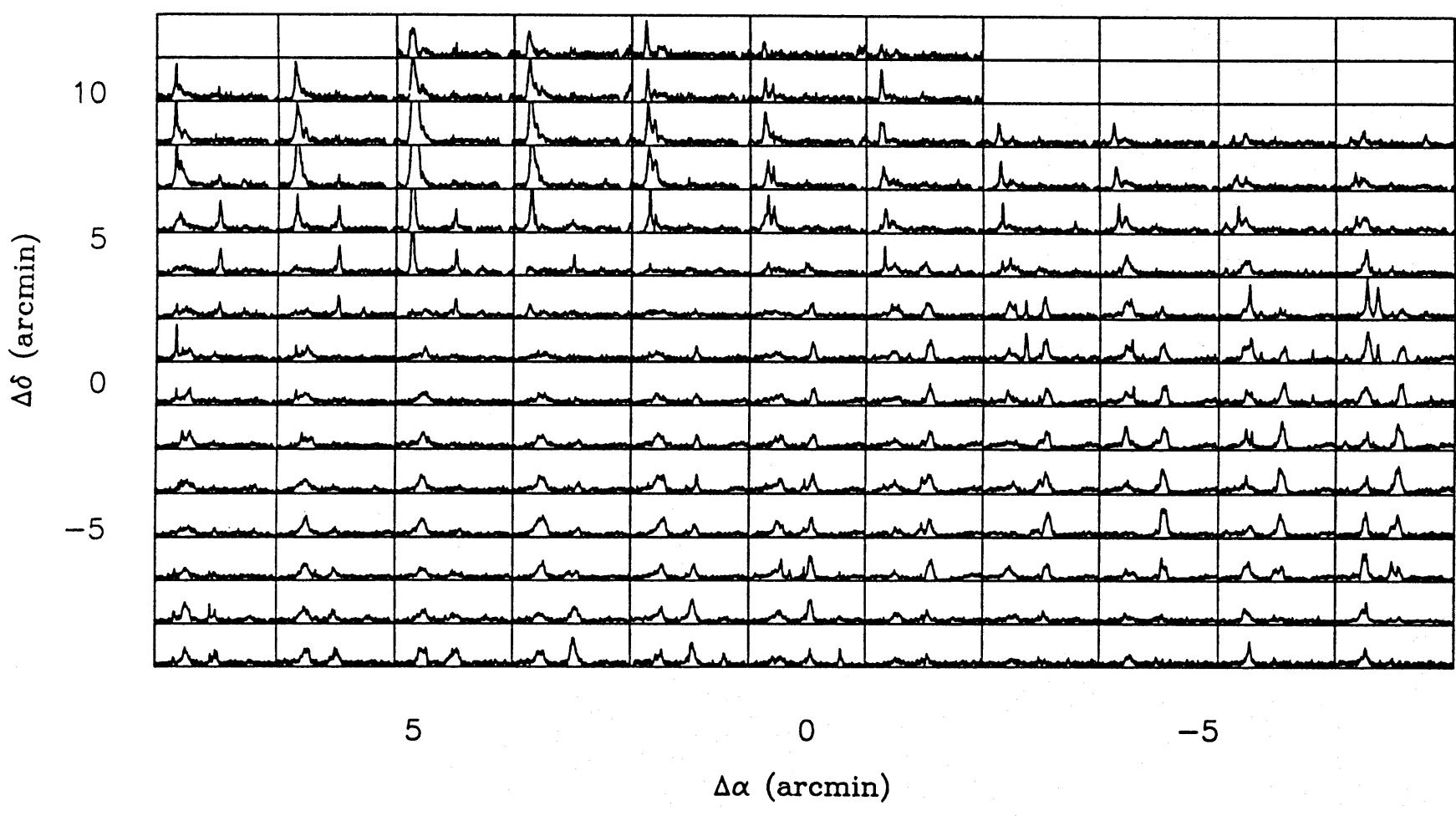

Fig. 10. Mosaic of the ${ }^{12} \mathrm{CO}$ emission observed on a 1.5 grid around HD 110432. Each spectrum is shown with a velocity range from -50 to $+50 \mathrm{~km} \mathrm{~s}^{-1}$ and an antenna temperature scale from -0.5 to $6 \mathrm{~K}$

peak values of $T_{R}^{*}\left({ }^{12} \mathrm{CO}\right) / T_{R}^{*}\left({ }^{13} \mathrm{CO}\right) \approx 1-3$ in the $J=1 \rightarrow$ 0 transition.

The $\mathrm{C}^{18} \mathrm{O} J=1 \rightarrow 0$ line was detected in 12 lines of sight, and the ${ }^{12} \mathrm{CO} / \mathrm{C}^{18} \mathrm{O}$ antenna temperature ratio as a function of ${ }^{12} \mathrm{CO}$ is included in Fig. 12 (right). As argued in section 3.1, the measurements towards HD 37903 and HD 53367 are discarded because the emission is likely to arise from background material. The $\mathrm{C}^{18} \mathrm{O}$ detections at offsets of $\left(3^{\prime},-6^{\prime}\right)$ from HD 80077 and $\left(-5^{\prime}, 0^{\prime}\right)$ from HD 110432 are ignored for a similar reason: no optical absorption lines are seen at the respective $\mathrm{C}^{18} \mathrm{O}$ radial velocities. The remaining ${ }^{13} \mathrm{CO} / \mathrm{C}^{18} \mathrm{O}$ antenna temperature ratios range from 7 (HD 94413) and 13 (HD 62542) to values around 18 (HD 169754) and 25 (HD 169454). $\mathrm{C}^{18} \mathrm{O}$ was not detected towards HD 80077, HD 110432, and BD $-14^{\circ} 5037$. The respective lower limits to the ${ }^{13} \mathrm{CO} / \mathrm{C}^{18} \mathrm{O}$ ratios are 13,16 , and 35. The overall interstellar $\left(\left[{ }^{13} \mathrm{C}\right] \cdot\left[{ }^{16} \mathrm{O}\right]\right) /\left(\left[{ }^{12} \mathrm{C}\right] \cdot\left[{ }^{18} \mathrm{O}\right]\right)$ isotope ratio is in the range 5.5-8 in the solar neighborhood. Thus, the ${ }^{13} \mathrm{CO} / \mathrm{C}^{18} \mathrm{O}$ ratios are generally consistent with or larger than the overall isotope ratio, suggesting that $\mathrm{C}^{18} \mathrm{O}$ may be underabundant by up to a factor of five.

By definition, translucent clouds are thin enough to allow penetration of ultraviolet (UV) radiation to a large extent. In the range $A_{V}=1-3 \mathrm{mag}$, the $\mathrm{CO}$ abundance is expected to increase rapidly with $A_{V}$ and to be a strong function of physical parameters such as the intensity of the UV field $I_{U V}$ and the density (van Dishoeck \& Black 1988). At depths between $A_{V}=0.5$ - 1.5 mag, selective photodissociation and temperature-sensitive ${ }^{13} \mathrm{C}$ isotope exchange reactions may increase the ${ }^{13} \mathrm{CO} / \mathrm{C}^{18} \mathrm{O}$ abundance ratio up to 20 times the $\left(\left[{ }^{13} \mathrm{C}\right] \cdot\left[{ }^{16} \mathrm{O}\right]\right) /\left(\left[{ }^{12} \mathrm{C}\right] \cdot\left[{ }^{18} \mathrm{O}\right]\right)$ iso- tope ratio, if the cloud is as cold as $10 \mathrm{~K}$. For warmer clouds with $T \approx 50 \mathrm{~K}$, the maximum effect is a factor of five. At depths of $A_{V}>1.5 \mathrm{mag}$ into a cloud, the ${ }^{13} \mathrm{CO} / \mathrm{C}^{18} \mathrm{O}$ abundance ratio decreases and approaches the overall isotope ratio (van Dishoeck \& Black 1988). If we assume that the ${ }^{13} \mathrm{CO}$ and $\mathrm{C}^{18} \mathrm{O}$ emission lines are both optically thin and that their antenna temperature ratio reflects the respective abundance ratio, then the values observed here indicate that for the clouds detected in $\mathrm{C}^{18} \mathrm{O}$, (i.e. the clouds towards HD 62542, HD 94413, HD 147889, and HD 169754), isotope-selective photodissociation plays only a minor role, consistent with the rather high temperatures of these clouds. For HD 62542, the ${ }^{13} \mathrm{CO} / \mathrm{C}^{18} \mathrm{O}$ ratio is remarkably constant at the two positions measured, even though the ${ }^{13} \mathrm{CO}$ antenna temperature differs by a factor of 4 . All stars with $\mathrm{C}^{18} \mathrm{O}$ detections have visual extinctions larger than 2 mag. The only exception is HD 62542 which has $A_{V} \approx 1 \mathrm{mag}$. The possibility exists that part of the emission towards HD 62542 arises from background material with larger extinctions. Also, the region where isotope selective photodissociation is important may be shifted to lower $A_{V}$ in regions of higher densities. For the other clouds where $\mathrm{C}^{18} \mathrm{O}$ has not been detected, isotope selective photodissociation appears to be more significant. The isotope selective photodissociation is also seen in the behavior of the ${ }^{12} \mathrm{CO}$ $/ \mathrm{C}^{18} \mathrm{O}$ ratio in Figure 12, although the interpretation of this plot is complicated by the fact that the optically thick ${ }^{12} \mathrm{CO}$ emission becomes stronger in warmer regions such as those towards HD 147889 and HD 62542. 
Table 2. Molecules

\begin{tabular}{|c|c|c|c|c|c|c|c|}
\hline Star & Molecule & $\begin{array}{l}\nu \\
\mathrm{MHz}\end{array}$ & $\begin{array}{l}\mathrm{t}_{\text {int }} \\
\min \end{array}$ & $\begin{array}{l}\int T_{A}^{*} d V \\
\mathrm{mK} \mathrm{km} \mathrm{s}\end{array}$ & $\begin{array}{l}V_{L S R} \\
\mathrm{~km} \mathrm{~s}^{-1}\end{array}$ & $\begin{array}{l}\Delta V \\
\mathrm{~km} \mathrm{~s}^{-1}\end{array}$ & $\begin{array}{l}T_{A}^{*} \dagger \\
\mathrm{mK}\end{array}$ \\
\hline HD 29647 & $\begin{array}{l}\mathrm{C}_{3} \mathrm{H}_{2} \\
\mathrm{CS}\end{array}$ & $\begin{array}{l}85338.89 \\
97980.968\end{array}$ & $\begin{array}{r}200 \\
74\end{array}$ & - & $\begin{array}{l}4.8: \\
4.8\end{array}$ & $\overline{0.8}$ & $\begin{array}{l}\leq 10 \\
198\end{array}$ \\
\hline HD 26571 & $\begin{array}{l}\mathrm{C}_{3} \mathrm{H}_{2} \\
\mathrm{CN}\end{array}$ & $\begin{array}{c}85338.89 \\
113490.982\end{array}$ & $\begin{array}{r}40 \\
188\end{array}$ & - & $\begin{array}{r}\text { 10.3: } \\
\text { 4.8: }\end{array}$ & - & $\begin{array}{l}\leq 25 \\
\leq 11\end{array}$ \\
\hline HD 53367 & $\mathrm{HCN}$ & 88631.847 & 90 & $\begin{array}{l}651 \\
391 \\
130\end{array}$ & $\begin{array}{l}17.2 \\
22.0^{a} \\
10.1^{a}\end{array}$ & $\begin{array}{l}2.5 \\
2.5 \\
2.5\end{array}$ & $\begin{array}{r}241^{a} \\
145^{a} \\
48^{a}\end{array}$ \\
\hline HD 62542 & $\begin{array}{l}\mathrm{HCO}^{+} \\
\mathrm{HNC} \\
\mathrm{CS} \\
\mathrm{SO}_{2} \\
\mathrm{CN}\end{array}$ & $\begin{array}{r}89188.518 \\
90663.543 \\
97980.968 \\
104029.416 \\
113490.982\end{array}$ & $\begin{array}{r}30 \\
66 \\
200 \\
30 \\
218\end{array}$ & $\begin{array}{c}- \\
- \\
177 \\
106 \\
35 \\
278 \\
- \\
130 \\
- \\
105\end{array}$ & $\begin{array}{c}-4.5: \\
-4.5: \\
-4.3 \\
0.5^{a} \\
-11.4^{a} \\
-3.9 \\
- \\
-5.0 \\
-5.0: \\
-5.0\end{array}$ & $\begin{array}{c}- \\
- \\
2.1 \\
2.1 \\
2.1 \\
1.8 \\
- \\
1.8 \\
- \\
1.9\end{array}$ & $\begin{array}{c}\leq 12 \\
\leq 15 \\
80^{a} \\
48^{a} \\
16^{a} \\
147 \\
\leq 23 \\
69 \\
\leq 28 \\
52\end{array}$ \\
\hline HD 63804 & CS & 97980.968 & 17 & - & 20.0 & - & $\leq 35$ \\
\hline HD 73882 & CS & 97980.968 & 17 & - & 9.7: & - & $\leq 35$ \\
\hline HD 80077 & $\begin{array}{l}\mathrm{HCN} \\
\mathrm{HCO}^{+} \\
\mathrm{CS} \\
\mathrm{SO}_{2} \\
\mathrm{CN}\end{array}$ & $\begin{array}{r}88631.847 \\
89188.518 \\
97980.968 \\
104029.416 \\
113490.982\end{array}$ & $\begin{array}{r}65 \\
50 \\
43 \\
20 \\
244\end{array}$ & $\begin{array}{c}- \\
435 \\
- \\
- \\
23\end{array}$ & $\begin{array}{l}8.0: \\
8.7 \\
8.0: \\
8.0: \\
7.8:\end{array}$ & $\begin{array}{c}- \\
2.5 \\
- \\
- \\
0.8:\end{array}$ & $\begin{array}{l}\leq 23 \\
165 \\
\leq 25 \\
\leq 40 \\
26:^{b}\end{array}$ \\
\hline HD 94413 & $\begin{array}{l}\mathrm{C}_{3} \mathrm{H}_{2} \\
\mathrm{HCN} \\
\mathrm{HCO}^{+} \\
\mathrm{CS} \\
\mathrm{CN}\end{array}$ & $\begin{array}{r}85338.89 \\
88631.847 \\
89188.518 \\
97980.968 \\
113490.982\end{array}$ & $\begin{array}{r}88 \\
20 \\
30 \\
148 \\
200\end{array}$ & $\begin{array}{c}- \\
- \\
220: \\
32 \\
-\end{array}$ & $\begin{array}{l}- \\
- \\
5.2: \\
4.6 \\
5.2:\end{array}$ & $\begin{array}{c}- \\
- \\
2.3: \\
0.4 \\
-\end{array}$ & $\begin{array}{l}\leq 20 \\
\leq 40 \\
92:^{b} \\
71 \\
\leq 23\end{array}$ \\
\hline HD 154368 & $\begin{array}{l}\mathrm{C}_{2} \mathrm{H} \\
\mathrm{C}_{2} \mathrm{H} \\
\mathrm{HCN} \\
\mathrm{HCO}^{+} \\
\mathrm{CS}\end{array}$ & $\begin{array}{l}87316.925 \\
87402.004 \\
88631.847 \\
89188.518 \\
97980.968\end{array}$ & $\begin{array}{r}35 \\
45 \\
40 \\
108 \\
50\end{array}$ & $\begin{array}{l}- \\
- \\
- \\
-\end{array}$ & $\begin{array}{l}5.8: \\
5.8: \\
5.8: \\
5.8: \\
5.8:\end{array}$ & $\begin{array}{l}- \\
- \\
- \\
-\end{array}$ & $\begin{array}{l}\leq 30 \\
\leq 25 \\
\leq 27 \\
\leq 36 \\
\leq 20\end{array}$ \\
\hline HD 169454 & $\begin{array}{l}\mathrm{C}_{2} \mathrm{H} \\
\mathrm{C}_{2} \mathrm{H} \\
\mathrm{HCN} \\
\mathrm{HCO}^{+}\end{array}$ & $\begin{array}{l}87316.925 \\
87402.004 \\
88631.847 \\
89188.518\end{array}$ & $\begin{array}{r}70 \\
30 \\
45 \\
105\end{array}$ & $\begin{array}{l}- \\
- \\
- \\
34:\end{array}$ & $\begin{array}{l}5.8: \\
5.8: \\
5.8: \\
5.8:\end{array}$ & $\begin{array}{l}- \\
- \\
- \\
0.5\end{array}$ & $\begin{array}{l}\leq 34 \\
\leq 25 \\
\leq 30 \\
63::^{b}\end{array}$ \\
\hline
\end{tabular}

$\dagger$ Upper limits correspond to $1 \sigma$ baseline rms per velocity channel.

a Velocities refer to center frequency of $88631.847 \mathrm{MHz}$ constrained 3-Gaussian fit: velocity difference $+4.842 \mathrm{~km} \mathrm{~s}^{-1}$ and $-7.064 \mathrm{~km} \mathrm{~s}^{-1}$, and intensity ratio 0.6 and 0.2 w.r.t. central component, respectively.

${ }^{b}$ marginal detection $(\approx 2 \sigma)$

\subsection{Morphology of the CO emission}

Many of the clouds observed here show small scale structure down to the resolution limit of the telescope. Localized intensity enhancements or "clumps" are present. Whether these clumps are spatially isolated structures is difficult to judge on the basis of ${ }^{12} \mathrm{CO} J=1 \rightarrow 0$ maps alone. The clouds are relatively thin, and a lot of the structure seen in the $\mathrm{CO}$ maps may reflect fluctuations in column density rather than total gas density. It has recently been demonstrated that the small scale structures seen in the HD 210121 translucent cloud are likely to reflect column density fluctuations rather than density variations (Gredel et al. 1992). The concept of physically and spatially distinct entities has been 
seriously criticized by Scalo (1990), who suggested that, even in case of giant complexes such as Taurus, the very limited dynamical range of detectable column densities may lead to misinterpretations of such apparent structure as "clumps".

It is interesting to note that many of the stars that show relatively small foreground column densities of $\mathrm{CH}^{+}$, but otherwise large column densities of $\mathrm{CH}, \mathrm{CN}$, and $\mathrm{C}_{2}$, appear to have simple CO emission profiles. Examples are HD 62542, HD 154368, and HD 169454. On the other hand, stars with large column densities of $\mathrm{CH}^{+}$have complex $\mathrm{CO}$ emission profiles, such as $\mathrm{HD} 80077$. If the three velocity components towards HD 80077 occur in the same spatial region, as argued in section 3.2.2, they are likely to arise in the region abundant in $\mathrm{CH}^{+}$, since the $\mathrm{CH}^{+}$appears close to the $+2 \mathrm{~km} \mathrm{~s}^{-1}$ seen in emission. There are other stars with complex CO profiles (e.g. HD 110432), where the observed $\mathrm{CO}$ line profile changes significantly across the map, indicating emission from spatially separate concentrations of gas. These stars do not show large $\mathrm{CH}^{+}$column densities.

\subsection{Velocity structure and masses}

In the following we analyze the velocity structure of the HD 62542, HD 80077, HD 154368 and HD 182985 translucent clouds to derive their three dimensional velocity dispersion. The emission towards the other clouds is too complex, and an unambiguous decomposition of the emission profiles into Gaussians is not possible. For HD 80077, the high quality ${ }^{13} \mathrm{CO}$ data are employed to derive velocity dispersions, for the others ${ }^{12} \mathrm{CO}$ is used. Results are presented in Table 3. Columns 2 and 3 list the mean full width at half maximum $\overline{\Delta V}$ and the mean radial velocity $\overline{V_{L S R}}$. The averages are weighted by $\int T_{A}^{*} d V$ over the map. Column 4 contains the dispersion of the line centroids of the individual map positions

$\sigma_{i n t}^{2}=\frac{N}{N-1} \frac{\Sigma \int T_{A}^{*} d V\left(V_{i}-\bar{V}\right)^{2}}{\Sigma \int T_{A}^{*} d V}$

The one dimensional velocity dispersion $\sigma_{z}$ in the clouds is then given by $\sigma_{z}=\left((\overline{\Delta V} / 2.35)^{2}+\sigma_{\text {int }}^{2}\right)^{1 / 2}$. It is seen that the velocity dispersions are small and do not vary much from cloud to cloud. As shown in Figure 6 of Gredel et al. (1991), the observed ${ }^{13} \mathrm{CO}$ line widths correlate well with the derived Doppler parameters from optical observations.

As discussed in the preceding section, the clumps seen in our maps may not have a physical significance. We nevertheless proceed to derive masses based on the velocity dispersions and the $\mathrm{CO}$ intensities. The standard conversion factor $N\left(\mathrm{H}_{2}\right) / I_{C O} \approx 2.8 \times 10^{20} \mathrm{~cm}^{-2} \mathrm{~K}^{-1} \mathrm{~s}$ (Bloemen et al. 1986; Magnani et al. 1988) is used to convert the CO intensities to molecular hydrogen column densities. The total mass of a clump can then be written as

$M_{H}=3.73 \times 10^{-7} \times A \times D^{2} \times<\int T_{A}^{*} d V>/ \eta_{\text {Moon }} M_{\odot}$

were $D$ is the distance to the clump in parsecs, and $A$ its area in $\operatorname{arcmin}^{2}$, defined by a boundary contour with $1 / e$ of maximum
Table 3. Velocity structure of individual regions

\begin{tabular}{lllll}
\hline Region & $\begin{array}{l}\Delta V^{\dagger} \\
\left(\mathrm{km} \mathrm{s}^{-1}\right)\end{array}$ & $\begin{array}{l}\bar{V}_{L S R}^{\dagger} \\
\left(\mathrm{km} \mathrm{s}^{-1}\right)\end{array}$ & $\begin{array}{l}\sigma_{\text {int }} \\
\left(\mathrm{km} \mathrm{s}^{-1}\right)\end{array}$ & $\begin{array}{l}\sigma_{z} \\
\left(\mathrm{~km} \mathrm{~s}^{-1}\right)\end{array}$ \\
\hline HD 62542 & $1.7(0.3)$ & $-4.4(0.4)$ & 0.4 & 0.8 \\
HD 80077 & & & & \\
$5 \mathrm{~km} \mathrm{~s}^{-1}$ & $1.0(0.3)$ & $5.0(0.3)$ & 0.2 & 0.5 \\
$8 \mathrm{~km} \mathrm{~s}^{-1}$ & $1.7(0.5)$ & $8.7(0.4)$ & 0.3 & 0.8 \\
HD 154368 & $1.3(0.3)$ & $5.8(0.2)$ & 0.2 & 0.6 \\
HD 182985 & $1.1(0.2)$ & $5.1(0.4)$ & 0.4 & 0.6 \\
HD 210121 & $1.4(0.4)$ & $-6.3(0.7)$ & 0.5 & 0.8 \\
\hline
\end{tabular}

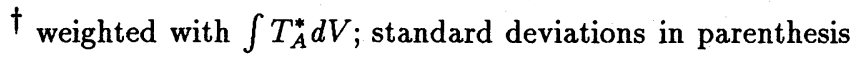

intensity. The derived masses are given in Table 4 . Total masses, including helium, are $M=1.4 \times M_{H}$. Towards HD 62542, the masses of the two clumps seen at offsets around $\left(2^{\prime},-5^{\prime}\right)$ and $\left(2^{\prime}, 5^{\prime}\right)$ are listed. Towards HD 80077, the masses of the clumps in the vicinity of the star at velocities of $+5 \mathrm{~km} \mathrm{~s}^{-1}$ and $+8 \mathrm{~km}$ $\mathrm{s}^{-1}$ are given. The entry for HD 154368 contains the mass of the cloud as a whole. The other maps do not show clumps with a boundary of at least $1 / e$ of maximum intensity.

Values of $D_{0}$ of $1500 \mathrm{pc}$ and $400 \mathrm{pc}$ are adopted for the distances to the clouds in front of HD 80077 and HD 154368, respectively, corresponding to half the distances to the respective stars. For HD 62542, the distance to the Gum nebula of $400 \mathrm{pc}$ is used. The masses derived from the $\mathrm{CO}$ intensities can be compared with those suggested by the virial theorem. If external pressure effects are neglected and if the clumps are treated as uniform and spherical, the virial equilibrium between the gravitational potential and the kinetic energy implies $M_{v i r, g}=5 R \sigma_{3 d}^{2} / 3 G$ where $R=\sqrt{A / \pi}$. The three dimensional velocity dispersion $\sigma_{3 d}$ is given by $\sqrt{3} \sigma_{z}$. The values of $M_{v i r, g}$ derived in such a manner are listed in column 6 of Table 4 . We have previously inferred that the clumps seen in the HD 210121 cloud are also not in gravitational virial equilibrium (Gredel et al. 1992). Note however that the CO masses listed in that paper are too large by a factor of 10 . The ratios of the $\mathrm{CO}$ to gravitational virial mass of individual clumps in the HD 210121 cloud are of the order of 0.03 , not 0.3 as listed in column 7 of Table 3 in Gredel et al. (1992). The HD 210121 cloud as a whole has a ratio of $M / M_{v i r, g}=0.07$. The statement that the HD 210121 cloud as a whole is close to gravitational virial equilibrium is therefore incorrect.

Including external pressure when deriving virial masses has the effect of reducing $M_{v i r}$. Recent estimates of the external pressure range from $P_{t o t} / k=1.4 \times 10^{4} \mathrm{~cm}^{-3} \mathrm{~K}$ for clouds in the solar neighborhood (Elmegreen 1989) to $P_{t o t} / k=2 \times 10^{4} \mathrm{~cm}^{-3}$ $\mathrm{K}$ for pressure bounded clouds in a turbulent interstellar medium that obey the empirical linewidth-size relationship (Maloney 1988). In order to estimate the lower limits to the virial masses if external pressure is taken into account, we adopt the values of Magnani (1987) of $\mathrm{n}_{\mathrm{H}}=1000 \mathrm{~cm}^{-3}$ and $\Delta \mathrm{V}=1 \mathrm{~km} \mathrm{~s}^{-1}$ for the external total hydrogen density and the linewidth, which would correspond to an external pressure of $P_{t o t} / k=2.8 \times 10^{4} \mathrm{~cm}^{-3}$ 
HD 62542

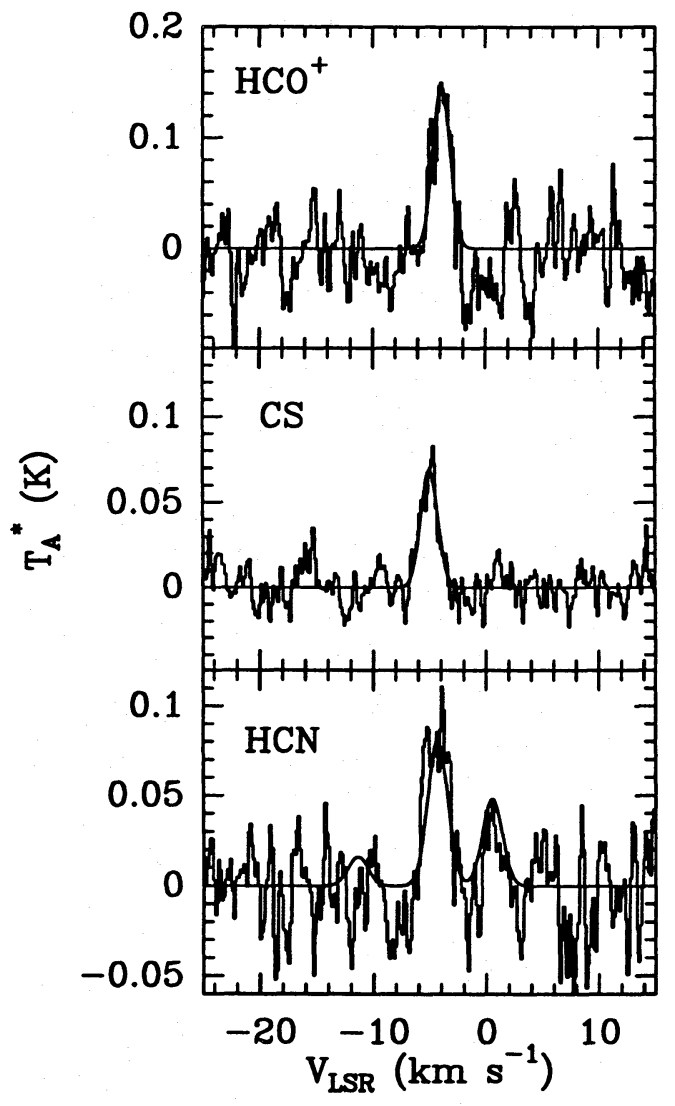

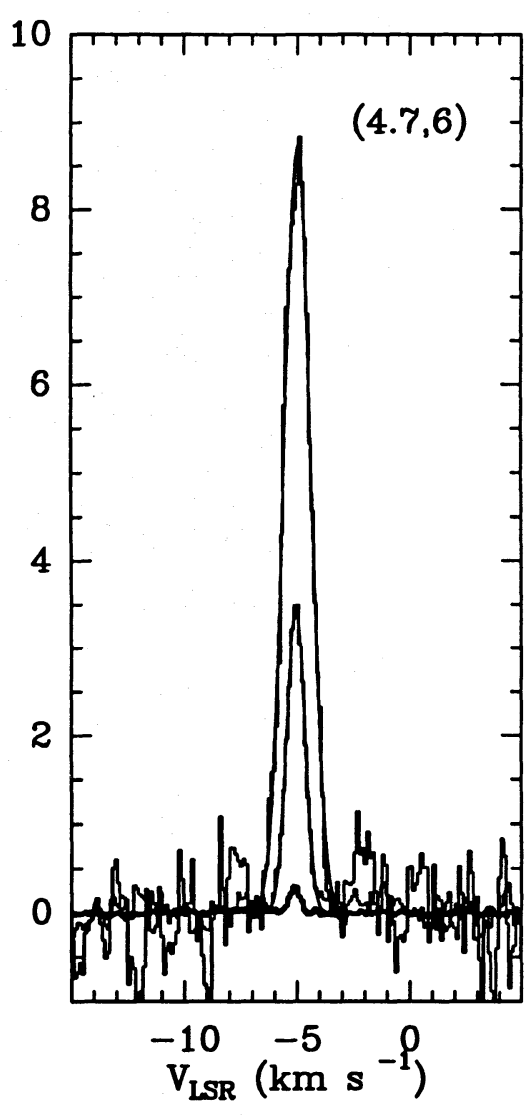

Fig. 11. Spectra of $\mathrm{HCO}^{+}, \mathrm{CS}$, and $\mathrm{HCN}$ detected in the HD 62542 cloud. Also shown are the ${ }^{12} \mathrm{CO},{ }^{13} \mathrm{CO}$, and $\mathrm{C}^{18} \mathrm{O}$ line profiles measured at an offset $\left(4 .^{\prime} 7,6^{\prime}\right)$ from the star. All CO spectra are drawn at the same scale
$\mathrm{K}$. The corresponding virial masses $M_{v i r}$ are listed in column 7 of Table 4. Column 8 gives the range of ratios $M / M_{\text {virial }}$ where $M_{v i r i a l}$ is either $M_{v i r, g}$ or $M_{v i r}$. It can be seen that external pressure does not significantly increase the ratio $M / M_{v i r}$ for the HD 62542 and HD 210121 clumps. These clouds have masses significantly smaller than the virial mass. However, the masses of the clumps towards HD 80077 and HD 154368 might exceed the virial mass.

An interesting relation between the observed virial parameter $\alpha_{o b s}=5 R \sigma_{3 d}^{2} / 3 G M$ and the mass $M$ derived from the integrated $\mathrm{CO}$ intensity was recently suggested by Bertoldi \& McKee (1992). These authors derived a relation of the form $\log \alpha=2.78\left(M_{J} / M\right)^{2 / 3}$ for pressure confined, spherical clumps in GMCs, where $M_{J}$ is the Jeans' mass. They reanalyzed existing data in the Ophiuchus, Orion B, Rosette, and Cepheus OB3 GMCs and found that the virial parameters of individual clumps follow the suggested correlation with the clump's mass. Different values of $M_{J}$ were derived for the four GMCs. The data presented here, including those obtained for the individual clumps in the HD 210121 cloud and that for the whole cloud, also follow the above correlation. This is illustrated in Figure 13 where $\log \alpha_{o b s}$ is plotted vs. $\log M / M_{\odot}$. The clumps in the HD 62542, HD 80077, and HD 210121, as well as the HD 154368 cloud as a whole, all fall onto the same line. It thus appears that all the translucent clumps plotted here have similar Jeans' masses, with a value around $M_{J} \approx 170 M_{\odot}$, represented by the straight line in Figure 13. The error margin is approximately $85 M_{\odot} \leq M_{J} \leq 340 M_{\odot}$, indicated by the dashed lines. A constant Jeans' mass is expected if the clumps are pressure confined and if the Alfvénic Mach number is of the order of unity (Bertoldi \& McKee 1992). The Jeans' mass derived above is smaller by a factor of a few compared to those found for the clumps in the Rossette, Orion B, and Cepheus OB3 molecular clouds, but the difference is probably not significant.

The preceding discussion adopts a conventional conversion factor in order to estimate hydrogen column densities and masses from CO $J=1-0$ line intensities. This conversion factor has been calibrated in dark clouds and GMCs rather than translucent clouds and it is usually justified for clouds that are self-gravitating and have optically thick $\mathrm{CO}$ emission. Even though there might be reason to question the applicability of the conventional conversion factor to clouds with weak $\mathrm{CO}$ line emission that appear not to be self-gravitating, other methods of estimating the hydrogen column densities yield masses that agree within factors of 5 or better. Such comparisons have been discussed in detail for the clouds towards HD 169454 and HD 210121 (Jannuzi et al. 1988; Gredel et al. 1992).

\section{Molecular column densities and abundances}

Although the abundances of molecules other than $\mathrm{CO}$ are very small in translucent clouds $\left(<10^{-7}\right.$ w.r.t. $\left.\mathrm{H}_{2}\right)$, they can still 

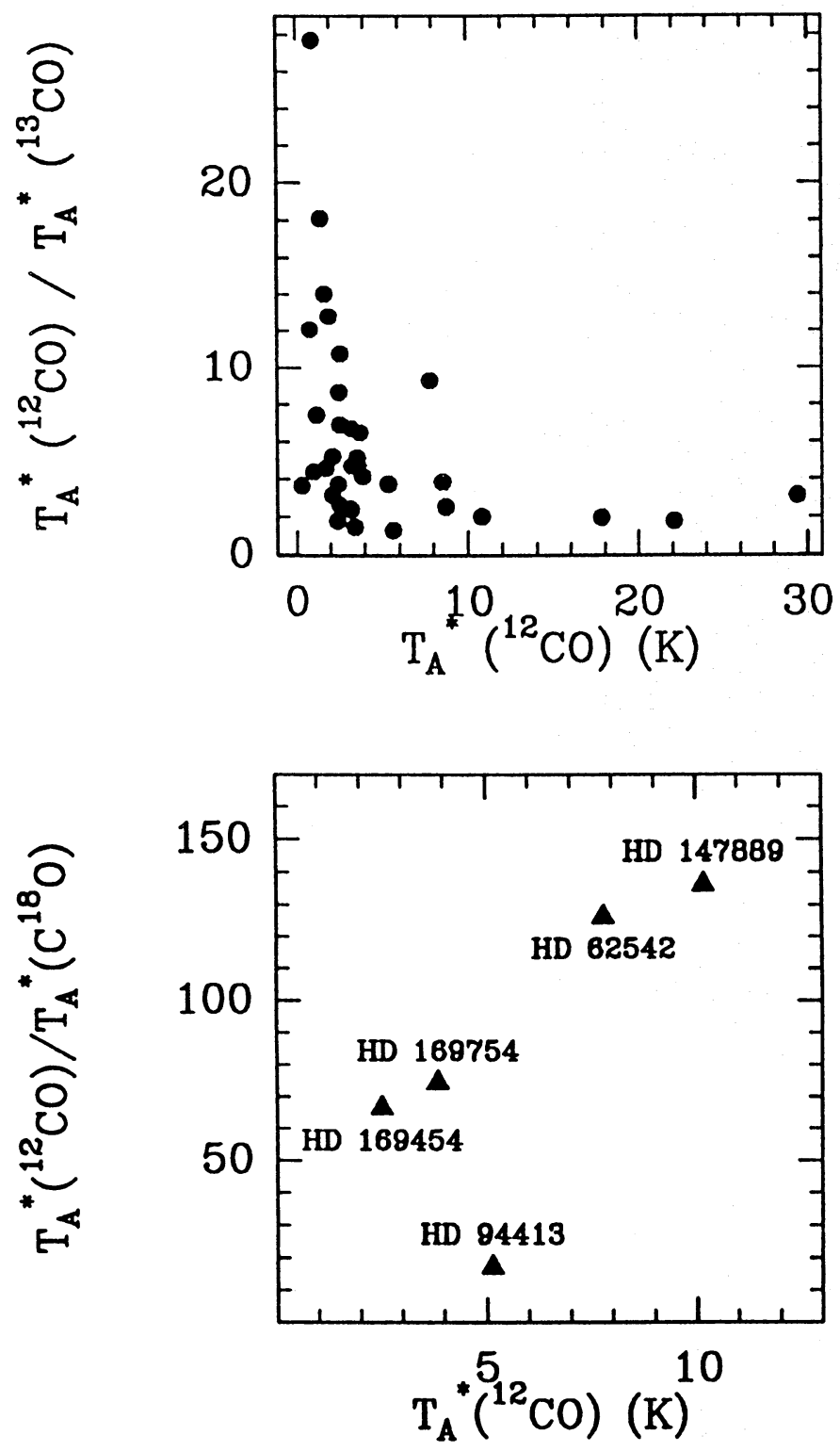

Fig. 12. The ${ }^{12} \mathrm{CO} /{ }^{13} \mathrm{CO}$ (left) and ${ }^{12} \mathrm{CO} / \mathrm{C}^{18} \mathrm{O}$ (right) antenna temperature ratios plotted vs. $T_{A}^{*}\left({ }^{12} \mathrm{CO}\right)$

be detected in relatively low density gas by their millimetre emission, as Table 2 shows. In particular, molecules with large dipole moments can be excited efficiently by electrons, which are expected to be abundant in these clouds, $x(\mathrm{e})=e / \mathrm{H}_{2}>10^{-5}$. This point has recently been demonstrated for CS by Drdla et al. (1989) and CN by Black \& van Dishoeck (1991). Still, only few polyatomic species have been seen and most of the entries in Table 2 are upper limits.

The column densities of the various species were derived following the procedure outlined by Drdla et al. (1989) and Jansen et al. (1993). In brief, the statistical equilibrium equations were solved for each species taking into account the processes of spontaneous emission, stimulated absorption and emission in the $2.7 \mathrm{~K}$ cosmic background radiation field, and collisional excitation and deexcitation. References to the adopted collisional

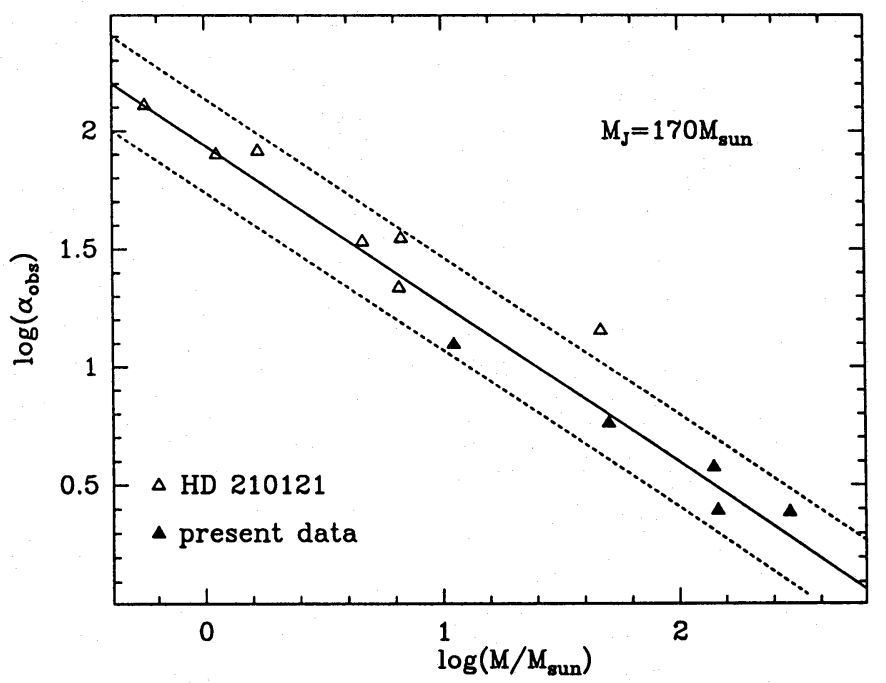

Fig. 13. Observed virial parameter $\log \alpha_{o b s}$ plotted as a function of total mass $\log M / M_{\odot}$

cross sections are given in Table 4 of Jansen et al. (1993). The electron fraction was taken to be $x(\mathrm{e}) \approx 5 \times 10^{-5}$, based on model calculations of van Dishoeck \& Black (1989) and analysis of CN observations of Black \& van Dishoeck (1991). Although this fraction varies with depth into the cloud and depends on physical parameters such as density, intensity of incident radiation and elemental depletions, it is expected to be a reasonable average. The radiative transfer was treated in an escape probability formalism.

A major uncertainty in the analysis is the density in the cloud. The excitation of the $\mathrm{C}_{2}$ and $\mathrm{CN}$ molecules obtained from optical absorption line observations usually indicates rather low densities of typically a few hundred $\mathrm{cm}^{-3}$ (Black \& van Dishoeck 1991). On the other hand, millimetre observations of CO $J=3 \rightarrow 2$ indicate in some cases higher densities of up to a few thousand $\mathrm{cm}^{-3}$ (van Dishoeck et al. 1991). We therefore present results for both cases in Table 5: the upper entry for each molecule indicates the column density if the lowest density permitted by observations is used; the second entry the result if the highest density is taken. For HD 62542, we also list results with $n\left(\mathrm{H}_{2}\right) \approx 2 \times 10^{4} \mathrm{~cm}^{-3}$, as inferred by Cardelli et al. (1990). The temperatures were taken to be those derived from the $\mathrm{C}_{2}$ analyses.

The resulting column densities are presented in Table 5, which includes the values for $\mathrm{CH}, \mathrm{C}_{2}$ and $\mathrm{CN}$ derived from the optical measurements. It is seen that the uncertainty in density translates into an uncertainty in derived column densities of nearly an order of magnitude: the higher the density, the lower the column density. Similarly, a higher electron fraction would result in lower column densities. The density could be further constrained by observations of higher excitation lines of molecules seen in emission, such as $\mathrm{HCO}^{+} 3-2$ (see Jansen et al. 1993). However, given the weakness of the 1-0 lines, the prospects for such observations are not very promising, 
Table 4. Masses of individual regions

\begin{tabular}{|c|c|c|c|c|c|c|c|c|}
\hline Region & $\begin{array}{l}\sigma_{3 d} \\
\left(\mathrm{~km} \mathrm{~s}^{-1}\right.\end{array}$ & $\begin{array}{l}\mathrm{A}^{a} \\
(\operatorname{arcmin})^{2}\end{array}$ & $\begin{array}{l}<\int T_{A}^{*} d V> \\
\left(\mathrm{K} \mathrm{km} \mathrm{s}{ }^{-1}\right)\end{array}$ & $\begin{array}{l}M_{H}^{b} \\
\left(\frac{D}{D_{0}}\right)^{2} M_{\odot}\end{array}$ & $\begin{array}{l}M_{v i r, g}^{b} \\
\left(\frac{D}{D_{0}}\right) M_{\odot}\end{array}$ & $\begin{array}{l}M_{v i r}^{b} \\
\left(\frac{D}{D_{0}}\right) M_{\odot}\end{array}$ & $M / M_{v i r i a l}^{c}$ & $\alpha_{o b s}^{d}$ \\
\hline $\begin{array}{l}\text { HD } 62542 \\
(2,-5) \\
(2,5)\end{array}$ & $\begin{array}{l}1.4 \\
1.4\end{array}$ & $\begin{array}{r}36 \\
8\end{array}$ & $\begin{array}{l}15.8 \\
15.0\end{array}$ & $\begin{array}{r}36 \\
8\end{array}$ & $\begin{array}{l}290 \\
140\end{array}$ & $\begin{array}{l}230 \\
110\end{array}$ & $\begin{array}{l}0.2 \\
0.1\end{array}$ & $\begin{array}{r}5.8 \\
12.5\end{array}$ \\
\hline $\begin{array}{l}\text { HD } 80077 \\
+5 \mathrm{~km} / \mathrm{s} \\
+8 \mathrm{~km} / \mathrm{s}\end{array}$ & $\begin{array}{l}0.9 \\
1.4\end{array}$ & $\begin{array}{r}22 \\
8\end{array}$ & $\begin{array}{r}5.1 \\
13.4\end{array}$ & $\begin{array}{l}104 \\
100\end{array}$ & $\begin{array}{l}360 \\
525\end{array}$ & $\begin{array}{l}0 \\
0\end{array}$ & $\begin{array}{l}0.4-1 \\
0.3-1\end{array}$ & $\begin{array}{l}2.5 \\
3.8\end{array}$ \\
\hline $\begin{array}{l}\text { HD } 154368 \\
\text { HD } 210121\end{array}$ & $\begin{array}{l}1.0 \\
1.3\end{array}$ & $\begin{array}{r}797 \\
1750\end{array}$ & $\begin{array}{l}4.0 \\
2.1\end{array}$ & $\begin{array}{r}210 \\
33\end{array}$ & $\begin{array}{l}715 \\
670\end{array}$ & $\begin{array}{l}290 \\
540\end{array}$ & $\begin{array}{l}0.4-1 \\
0.1\end{array}$ & $\begin{array}{r}2.4 \\
14.3\end{array}$ \\
\hline
\end{tabular}

HD 62542 being the only exception. The uncertainty in temperature results in smaller variations than that in density.

Table 5 includes the results from the translucent model of van Dishoeck \& Black (1989) for the HD 29647 cloud, as well as observations of other molecules towards this cloud by Crutcher (1985). The most remarkable finding is that the $\mathrm{C}_{2} \mathrm{H}$ molecule is not detected in any of the clouds. The gas-phase chemistry of this radical is intimately connected to that of $\mathrm{C}_{2}$, which has quite large column densities. For the low end of the density range, the observed values are still just consistent with the models, but if the higher densities apply, they are factors of 3-10 lower. The most likely explanation would be an underestimate of the $\mathrm{C}_{2} \mathrm{H}$ photodissociation rate, although it is unlikely to be in error by as much as an order of magnitude (van Dishoeck 1988). The complex carbon-bearing molecule $\mathrm{C}_{3} \mathrm{H}_{2}$ is also not detected in any of the clouds, even though Madden et al. (1989) find a very weak line at $18.3 \mathrm{GHz}$ towards HD 29647. The column density inferred from this line is a factor of two below the upper limits listed in Table 5 from searches for the $85.3 \mathrm{GHz}$ line. This lack of more complex carbon-bearing molecules is somewhat surprising, since they are found quite abundantly in some dense cores, where their formation is thought to be stimulated by large amounts of atomic $\mathrm{C}$ and $\mathrm{C}^{+}$in the gas phase (Suzuki 1983; Suzuki et al. 1988, 1992). These translucent clouds contain plenty of atomic carbon, but even $\mathrm{C}_{2} \mathrm{H}$ is hardly seen.

On the other hand, the $\mathrm{HCO}^{+}$ion is detected in a number of clouds, most notably towards HD 62542. Because of rapid dissociative recombination with the abundant electrons in the cloud, this is quite surprising and the observed values are up to an order of magnitude larger than the models if the low densities apply. The large HCN column densities inferred for HD 29647 and HD 62542 are also remarkable, although the uncertainty in density precludes any conclusions about significant variations from cloud to cloud. At low densities, the observed HCN values are again significantly higher than the model results, but at higher densities they are comparable. Note also that the model $\mathrm{HCN}$ values are expected to increase at higher density.
The observed CS column densities are reasonably consistent with the model results of Drdla et al. (1989), especially if the variation of nearly an order of magnitude due to uncertainties in key molecular parameters and the gas-phase sulfur abundance is taken into account.

The column densities of the various molecules with respect to that of $\mathrm{H}_{2}$ are summarized in Table 6. The $\mathrm{H}_{2}$ column densities along the lines of sight were estimated from the measured total $A_{V}$ and from the empirical relation between $\mathrm{CH}$ and $\mathrm{H}_{2}$ (Danks et al. 1984; see van Dishoeck \& Black 1989). Although some of the millimetre emission may come from material located behind the star, this is not expected to change the numbers by more than a factor of two for the clouds listed in Table 6. The resulting abundances $X=N(\mathrm{AB}) / N\left(\mathrm{H}_{2}\right)$ can be compared with those found in other, denser clouds. A particularly interesting case is the small reflection nebula IC 63, for which Jansen et al. (1993) have recently presented accurate abundances of a number of the same species. Compared with the translucent clouds studied in this work, IC 63 is exposed to more intense radiation $\left(I_{U V} \approx 900\right)$ and is denser, $n\left(\mathrm{H}_{2}\right) \approx 5 \times 10^{4} \mathrm{~cm}^{-3}$. The IC 63 cloud resembles that towards HD 62542 in the sense that both of them may be rather dense clumps of gas with stellar winds having blown away most of the surrounding more diffuse gas. It is seen that the abundances of most species are similar within an order of magnitude. Diatomic molecules such as $\mathrm{CN}$ and CS appear relatively more abundant towards HD 62542, whereas polyatomic species such as $\mathrm{C}_{2} \mathrm{H}$ are probably more prominent in the IC 63 cloud.

Another interesting comparison is that between the cloud towards HD 29647 and the TMC-1 core, which is located only $10^{\prime}$ away. The abundances of most polyatomic molecules appear significantly higher in TMC-1, especially for $\mathrm{C}_{2} \mathrm{H}$ and $\mathrm{C}_{3} \mathrm{H}_{2}$, emphasizing again the unique nature of TMC-1 regarding complex carbon-bearing molecules. 
Table 5. Molecular column densities (in $\left.\mathrm{cm}^{-2}\right)^{a}$

\begin{tabular}{|c|c|c|c|c|c|c|}
\hline Species & HD29647 & HD62542 & HD94413 & HD154368 & HD169454 & Model $^{b}$ \\
\hline $\begin{array}{l}\mathrm{H}_{2} \ldots \ldots \ldots \\
\mathrm{CO} \ldots \ldots \ldots\end{array}$ & $\begin{aligned} & 3.0(21) \\
\geq & 4(16) \\
\geq & 1(16)\end{aligned}$ & $\begin{array}{l}1.0(21) \\
5.0(16) \\
1.4(16)\end{array}$ & $\begin{array}{l}1.3(21) \\
1.2(16) \\
7.0(15)\end{array}$ & $\begin{array}{l}1.8(21) \\
1.5(16) \\
6.0(15)\end{array}$ & $\begin{array}{l}1.6(21) \\
1.8(16) \\
5.5(15)\end{array}$ & $\begin{array}{l}3.0(21) \\
2.9(17)\end{array}$ \\
\hline${ }^{13} \mathrm{CO} \ldots \ldots$ & $\begin{array}{l}1.0(16) \\
4.0(15)\end{array}$ & $\begin{array}{l}1.1(15) \\
6.5(14)\end{array}$ & $\begin{array}{l}2.0(15) \\
1.4(15)\end{array}$ & $\begin{array}{l}1.0(15) \\
6.0(14)\end{array}$ & $\begin{array}{l}2.0(15) \\
9.0(14)\end{array}$ & $3.8(15)^{f}$ \\
\hline $\mathrm{C}^{18} \mathrm{O} \ldots \ldots$ & $\begin{array}{l}1.2(15)^{c} \\
6.0(14)^{c}\end{array}$ & $\begin{array}{l}2.0(13) \\
1.5(13)\end{array}$ & $\begin{array}{l}1.2(14) \\
1.0(14)\end{array}$ & $\begin{array}{l}\cdots \\
\ldots\end{array}$ & $\begin{array}{l}4.0(13) \\
2.0(13)\end{array}$ & $1.3(14)$ \\
\hline $\mathrm{CH}^{d} \ldots \ldots$ & $1.5(14)$ & $3.8(13)$ & $4.4(13)$ & $5.4(13)$ & $4.4(13)$ & $1.1(14)$ \\
\hline $\mathrm{C}_{2}^{d} \ldots \ldots \ldots \ldots$ & $1.7(14)$ & $8.0(13)$ & $3.5(13)$ & $5.8(13)$ & $7.0(13)$ & $1.6(14)$ \\
\hline $\mathrm{CN}^{d} \ldots \ldots \ldots$ & $1.6(14)$ & $4.2(13)$ & $5.2(13)$ & $3.3(13)$ & $4.2(13)$ & $8.0(13)$ \\
\hline CS $\ldots \ldots \ldots$ & $\begin{array}{l}1.3(14)^{c} \\
7.5(12)^{c}\end{array}$ & $\begin{array}{l}6.5(13) \\
8.0(12) \\
1.0(12)\end{array}$ & $\begin{array}{l}9.0(12) \\
1.3(12)\end{array}$ & $\begin{array}{l}<1.3(13) \\
<3.0(12)\end{array}$ & $\begin{array}{l}2.8(13)^{e} \\
4.2(12)^{e}\end{array}$ & \\
\hline $\mathrm{C}_{2} \mathrm{H} \ldots \ldots$ & $\begin{array}{l}<1.2(14)^{c} \\
<9.0(12)^{c}\end{array}$ & $\begin{array}{l}<2.0(13) \\
<3.0(12) \\
<7.0(11)\end{array}$ & $\begin{array}{l}\cdots \\
\cdots\end{array}$ & $\begin{array}{l}<1.2(13) \\
<3.5(12)\end{array}$ & $\begin{array}{l}<4.0(13) \\
<8.0(12)\end{array}$ & $2.7(13)$ \\
\hline $\mathrm{HCN} \ldots . .$. & $\begin{array}{l}7.0(13)^{c} \\
4.0(12)^{c}\end{array}$ & $\begin{array}{l}8.0(13) \\
1.0(13) \\
1.2(12)\end{array}$ & $\begin{array}{l}<9.0(12) \\
<1.3(12)\end{array}$ & $\begin{array}{l}<1.6(13) \\
<3.0(12)\end{array}$ & $\begin{array}{l}<1.6(13) \\
<2.5(12)\end{array}$ & $2.4(12)$ \\
\hline $\mathrm{HCO}^{+} \ldots \ldots$ & $\begin{array}{l}2.5(13)^{c} \\
1.5(12)^{c}\end{array}$ & $\begin{array}{l}2.2(13) \\
2.5(12) \\
4.0(11)\end{array}$ & $\begin{array}{l}\text { 8.7(12): } \\
1.3(12):\end{array}$ & $\begin{array}{l}<3.8(12) \\
<7.6(11)\end{array}$ & $\begin{array}{l}3.8(12) \\
6.0(11)\end{array}$ & $3.4(12)$ \\
\hline $\mathrm{C}_{3} \mathrm{H}_{2} \ldots \ldots$ & $\begin{array}{l}<1.0(13) \\
<8.0(11)\end{array}$ & $\begin{array}{l}<1.0(13) \\
<1.6(12) \\
<2.4(11)\end{array}$ & $\begin{array}{l}<4.5(12) \\
<7.0(11)\end{array}$ & $\begin{array}{l}\cdots \\
\cdots\end{array}$ & $\begin{array}{l}\cdots \\
\cdots\end{array}$ & \\
\hline
\end{tabular}

Footnotes to Table 5:

a The upper entry for each species corresponds to the lowest density allowed by the observations, the second entry to the highest density consistent with the data. The third entry for $\mathrm{HD} 62542$ corresponds to $n\left(\mathrm{H}_{2}\right)=2 \times 10^{4} \mathrm{~cm}^{-3}$. A colon indicates an uncertain value. Adopted physical parameters for each star: HD 29647: $T=15 \mathrm{~K}, n\left(\mathrm{H}_{2}\right)=350$ and 5000 $\mathrm{cm}^{-3}$; HD 62542: $T=40 \mathrm{~K}, n\left(\mathrm{H}_{2}\right)=300,2000$ and $20000 \mathrm{~cm}^{-3}$, HD 94413: $T=40 \mathrm{~K}, n\left(\mathrm{H}_{2}\right)=500$ and $3000 \mathrm{~cm}^{-3}$, HD 154368: $T=25 \mathrm{~K}, n\left(\mathrm{H}_{2}\right)=250$ and $1000 \mathrm{~cm}^{-3}, \mathrm{HD} 169454: T=15 \mathrm{~K}$, $n\left(\mathrm{H}_{2}\right)=300$ and $1500 \mathrm{~cm}^{-3}$.

\section{Concluding remarks}

We have presented millimetre emission line observations of $\mathrm{CO}$ and other molecules towards stars behind translucent molecular clouds. Through ${ }^{12} \mathrm{CO} J=1 \rightarrow 0$ maps, we have surveyed the extent of the molecular material and its kinematic structure. For some clouds, the $\mathrm{CO}$ emission is well characterized by a single component, which does not vary drastically across the
${ }^{b}$ Model for HD 29647 cloud by van Dishoeck \& Black (1989), which is similar to model T5 of van Dishoeck \& Black (1988).

${ }^{c}$ Based on observations of Crutcher (1985).

${ }^{d}$ From optical absorption lines.

e Based on observations of Drdla et al. (1989).

$f$ Strongly dependent on adopted temperature.

map (e.g. HD 62542, HD 94413, HD 154368, HD 169454). In other cases, multiple components are found over a narrow velocity range, some of which vary in a self-similar manner across the cloud (HD 80077), whereas others show more independent fluctuations (e.g. HD 110432). The $\mathrm{C}^{18} \mathrm{O} J=1 \rightarrow 0$ line was detected towards five stars. The ${ }^{13} \mathrm{CO} / \mathrm{C}^{18} \mathrm{O}$ ratio is similar to or larger than the cosmic $\left(\left[{ }^{13} \mathrm{C}\right] \cdot\left[{ }^{16} \mathrm{O}\right]\right) /\left(\left[{ }^{12} \mathrm{C}\right] \cdot\left[{ }^{18} \mathrm{O}\right]\right)$ iso- 
Table 6. Molecular abundances relative to $\mathrm{H}_{2}$

\begin{tabular}{|c|c|c|c|c|c|c|c|}
\hline Species & HD29647 & HD62542 & HD94413 & HD154368 & HD169454 & IC 63 & TMC-1 \\
\hline $\mathrm{H}_{2} \ldots \ldots \ldots$ & 1.0 & 1.0 & 1.0 & 1.0 & 1.0 & 1.0 & 1.0 \\
\hline $\mathrm{CO} \ldots \ldots \ldots$ & $\begin{array}{l}\geq 1.3(-5) \\
>4.0(-6)\end{array}$ & $\begin{array}{l}5.0(-5) \\
1.4(-5)\end{array}$ & $\begin{array}{l}9.2(-6) \\
5.4(-6)\end{array}$ & $\begin{array}{l}8.3(-6) \\
3.3(-6)\end{array}$ & $\begin{array}{l}1.1(-5) \\
3.4(-6)\end{array}$ & $6.0(-5)$ & $8(-5)$ \\
\hline${ }^{13} \mathrm{CO} \ldots \ldots$ & $\begin{array}{l}3.3(-6) \\
1.3(-6)\end{array}$ & $\begin{array}{l}1.1(-6) \\
6.5(-7)\end{array}$ & $\begin{array}{l}1.5(-6) \\
1.1(-6)\end{array}$ & $\begin{array}{l}5.6(-7) \\
3.3(-7)\end{array}$ & $\begin{array}{l}1.3(-6) \\
5.6(-7)\end{array}$ & $4.4(-7)$ & $4(-6)$ \\
\hline $\mathrm{C}^{18} \mathrm{O} \ldots \ldots$ & $\begin{array}{l}4.0(-7) \\
2.0(-7)\end{array}$ & $\begin{array}{l}2.0(-8) \\
1.5(-8)\end{array}$ & $\begin{array}{l}9.2(-8) \\
7.7(-8)\end{array}$ & $\begin{array}{l}\ldots \\
\ldots\end{array}$ & $\begin{array}{l}2.5(-8) \\
1.3(-8)\end{array}$ & $8.0(-8)$ & \\
\hline $\mathrm{CH}^{b} \ldots$ & $5.0(-8)$ & $3.8(-8)$ & $3.4(-8)$ & $3.0(-8)$ & $2.8(=8)$ & $\cdots$ & $2(-8)$ \\
\hline $\mathrm{C}_{2}^{b} \ldots \ldots \ldots$ & $5.7(-8)$ & $8.0(-8)$ & $2.7(-8)$ & $3.2(-8)$ & $4.4(-8)$ & $\cdots$ & $\cdots$ \\
\hline $\mathrm{CN}^{b} \ldots \ldots$ & $5.3(-8)$ & $4.2(-8)$ & $4.0(-8)$ & $1.8(-8)$ & $2.6(-8)$ & $4.8(-9)$ & $3(-8)$ \\
\hline CS $\ldots \ldots \ldots$ & $\begin{array}{l}4.3(-8) \\
2.5(-9)\end{array}$ & $\begin{array}{l}6.5(-8) \\
8.0(-9) \\
1.0(-9)\end{array}$ & $\begin{array}{l}6.9(-9) \\
1.0(-9)\end{array}$ & $\begin{array}{l}<7.2(-9) \\
<1.7(-9)\end{array}$ & $\begin{array}{l}1.8(-8) \\
2.6(-9)\end{array}$ & $1.5(-9)$ & $3(-8)$ \\
\hline $\mathrm{C}_{2} \mathrm{H} \ldots \ldots$ & $\begin{array}{l}<4.0(-8) \\
<3.0(-9)\end{array}$ & $\begin{array}{l}<2.0(-8) \\
<3.0(-9) \\
<7.0(-10)\end{array}$ & $\begin{array}{l}\cdots \\
\ldots\end{array}$ & $\begin{array}{l}<6.7(-9) \\
<1.9(-9)\end{array}$ & $\begin{array}{l}<2.5(-8) \\
<5.0(-9)\end{array}$ & $4.0(-9)$ & $8(-8)$ \\
\hline $\mathrm{HCN} \ldots \ldots$. & $\begin{array}{l}2.3(-8) \\
1.3(-9)\end{array}$ & $\begin{array}{l}8.0(-8) \\
1.0(-8) \\
1.2(-9)\end{array}$ & $\begin{array}{l}<6.9(-9) \\
<1.0(-9)\end{array}$ & $\begin{array}{l}<8.9(-9) \\
<1.7(-9)\end{array}$ & $\begin{array}{l}<1.0(-8) \\
<1.6(-9)\end{array}$ & $3.6(-9)$ & $2(-8)$ \\
\hline $\mathrm{HCO}^{+} \ldots \ldots$ & $\begin{array}{l}8.3(-9) \\
5.0(-10)\end{array}$ & $\begin{array}{l}2.2(-8) \\
2.5(-9) \\
4.0(-10)\end{array}$ & $\begin{array}{l}\text { 6.7(-9): } \\
1.0(-9):\end{array}$ & $\begin{array}{l}<2.1(-9) \\
<4.2(-10)\end{array}$ & $\begin{array}{l}2.4(-9) \\
3.8(-10)\end{array}$ & $3.6(-9)$ & $2(-8)$ \\
\hline $\mathrm{C}_{3} \mathrm{H}_{2} \ldots \ldots \ldots$ & $\begin{array}{l}<3.0(-9) \\
<2.7(-10)\end{array}$ & $\begin{array}{l}<1.0(-8) \\
<1.6(-9) \\
<2.4(-10)\end{array}$ & $\begin{array}{l}<3.5(-9) \\
<5.4(-10)\end{array}$ & $\cdots$ & $\cdots$ & $\ldots$ & $2(-8)$ \\
\hline
\end{tabular}

a The upper entry for each molecule corresponds to the lowest density allowed by the observations, the second entry to the highest density consistent with the data. The third entry for HD 62542 refers to $n=2 \times 10^{4} \mathrm{~cm}^{-3}$. A colon indicates an uncertain value. See Table 5 for details.

${ }^{b}$ From optical absorption line observations.

tope ratio by up to factors of five, suggesting that towards some clouds isotope selective photodissociation may play a role.

Observations of molecules other than $\mathrm{CO}$ have been presented towards a few well-characterized translucent clouds. The uncertainty in density unfortunately results in large uncertainties in the derived column densities and abundances, but a few general trends are clear. Diatomic molecules such as $\mathrm{CN}$ and $\mathrm{C}_{2}$ are quite abundant in translucent clouds, but polyatomic species such as $\mathrm{C}_{2} \mathrm{H}$ and $\mathrm{C}_{3} \mathrm{H}_{2}$ are not detected. On the other hand, $\mathrm{HCN}$ appears remarkably abundant in at least two clouds and the abundance of $\mathrm{HCO}^{+}$is similar to that found in dense clouds. More detailed chemical modeling is needed to properly interpret these observations, and such work is currently in progress.
Acknowledgements. The authors are grateful to Cor de Vries for performing the absorption line observations towards HD 182985. We appreciate the constructive comments of the referee, Barry E. Turner. This work was supported by the Netherlands Organization for Scientific Research, NWO. Research in astrochemistry at the University of Arizona is supported by NASA through grant NAGW-2255.

\section{References}

Bertoldi, F., McKee, C.F., 1992, ApJ 395, 140

Black, J.H., van Dishoeck, E.F., 1991, ApJ 369, L9

Bloemen, J.B.G.M., Strong, A.W., Blitz, L., Cohen, R.S., Dame, T.M., Grabelsky, D.A., Hermsen, W., Lebrun, F., Mayer-Hasselwander, H.A., Thaddeus, P., 1986, A\&A 154, 25

Boden, K.-P., Heithausen, A., 1993, A\&A 268, 255 
Booth, R.S., Delgado, G., Hagström, M., Johansson, L.E.B., Murphy, D.C., Olberg, M., Whyborn, N.D., Greve, A., Hansson, B., Lindström, C.O., Rydberg, A., 1989, A\&A 216, 315

Cardelli, J.A., Savage, B.D., 1988 ApJ 325, 864

Cardelli, J.A., Suntzeff, N.B., Edgar, R.J., Savage, B.D., 1990, ApJ 362,551

Crutcher, R.M., 1985, ApJ 288, 604

Danks, A.C., Federman, S.R., Lambert, D.L., 1984, A\&A 130, 62

de Vries, H.W., Heithausen, A., Thaddeus, P., 1987, ApJ 319, 723

Drdla, K., Knapp, G.R., van Dishoeck, E.F., 1989, ApJ 345, 815

Elmegreen, B.G. 1989, ApJ 338, 178

Falgarone, E., Pérault, M., 1988, A\&A 205, L1

Falgarone, E., Phillips, T.G., 1990, ApJ 359, 344

Falgarone, E., Phillips, T.G., Walker, C.K., 1991, ApJ 378, 186

Gredel, R., Münch, G., 1986, A\&A 154, 336

Gredel, R., van Dishoeck, E.F., Black, J.H., 1991, A\&A 251, 625

Gredel, R., van Dishoeck, E.F., de Vries, C.P., Black, J.H., 1992, A\&A 257,245

Gredel, R., van Dishoeck, E.F., Black, J.H., 1993, A\&A 269, 477

Großmann, V., Heithausen, A., Meyerdierks, H., Mebold, U., 1990, A\&A 240,400

Großmann, V., Heithausen, A., 1992, A\&A 264, 195

Heithausen, A., Mebold, U., de Vries, H.W., 1987, A\&A 179, 263

Jannuzi, B.T., Black, J.H., Lada, C.J., van Dishoeck, E.F., 1988, ApJ 332,995

Jansen, D.J., van Dishoeck, E.F., Black, J.H., 1993, A\&A in press

Keto, E.R., Myers, P.C., 1986, ApJ 304, 466

Kutner, M.L, Ulich, B.L., 1981, ApJ 250, 341

Madden, S.C., Irvine, W.M., Matthews, H.E., Friberg, P., Swade, D.A., 1989, AJ 97, 1403

Magnani, L., Blitz, L., Mundy, L., 1985, ApJ 295, 402

Magnani, L. 1987, Ph. D. thesis, University of Maryland

Magnani, L., Blitz, L., Wouterloot, J.G.A., 1988, ApJ 326, 909

Magnani, L., Siskind, L., 1990, ApJ 359, 355
Maloney, P. 1988, ApJ 334, 761

Meyerdierks, H., Brouillet, N., Mebold, U., 1990, A\&A 230, 172

Mebold, U., Heithausen, A., Reif, K., 1987, A\&A 180, 213

O’ Donnell, J.E., Cardelli, J.A., Churchwell, E., 1992, AJ 104, 2161

Nyman, L.-Å ., Bronfman, L., Thaddeus, P., 1989, A\&A 216, 185

Polk, K.S., Knapp, G.R., Stark, A.A., Wilson, R.W., 1988, ApJ 332, 432

Pound, M.W., Bania, T.M., Wilson, R.W., 1990, ApJ 351, 165

Scalo, J. 1990, in Physical Processes in Fragmentation and Star Formation (eds. R. Capuzzo-Dolcetta, C. Chiosi, and A. Di Fazio ), p. 151, Kluwer, Dordrecht

Stark, R., 1993, Ph. D. Thesis, University of Leiden, The Netherlands Suzuki, H., 1983, ApJ 272, 579

Suzuki, H., Ohishi, M., Kaifu, N., Kasuga, T., Ishikawa, S., Miyaji, T., 1988, Vistas Astron. 31, 459

Suzuki, H., Yamamoto, S., Ohishi, M., Kaifu, N., Ishikawa, S.-I., Hirahara, Y., Takano, S., 1992, ApJ 392, 551

Turner, B.E., Rickard, L.J, Xu, L.-P., 1989, ApJ 344, 292

Turner, B.E., Xu, L.-P. Rickard, L.J. 1992, ApJ 391, 158

Turner, B.E. 1993a, ApJ 410, 140

Turner, B.E. 1993b, ApJ 411, 219

van Dishoeck, E.F., 1988, in Rate Coefficients in Astrochemistry (eds.

T.J. Millar \& D.A. Williams), p. 49, Kluwer, Dordrecht

van Dishoeck, E.F. Black, J.H., 1988, ApJ 44, 771

van Dishoeck, E.F. Black, J.H., 1989, ApJ 340, 273

van Dishoeck, E.F., Black, J.H., Phillips, T.G., Gredel, R., 1991, ApJ 366,141

van Dishoeck, E.F., de Zeeuw, P.T., 1984, MNRAS 206, 383

Verschuur, G.L. 1991, Ap\&SS 185, 305

Zensen, W., 1984, Ph. D. Dissertation, University of Cologne

This article was processed by the author using Springer-Verlag TEX A\&A macro package 1992. 